\title{
ISCCM Guidelines for the Use of Non-invasive Ventilation in Acute Respiratory Failure in Adult ICUs
}

Rajesh Chawla ${ }^{1}$, Subhal B Dixit ${ }^{2}$, Kapil Gangadhar Zirpe $^{3}$, Dhruva Chaudhry ${ }^{4}$, G C Khilnani ${ }^{5}$, Yatin Mehta ${ }^{6}$, Khalid Ismail Khatib ${ }^{7}$, Bharat G Jagiasi ${ }^{8}$, Gunjan Chanchalani ${ }^{9}$, Rajesh C Mishra ${ }^{10}$, Srinivas Samavedam ${ }^{11}$, Deepak Govil ${ }^{12}$, Sachin Gupta ${ }^{13}$, Shirish Prayag ${ }^{14}$, Suresh Ramasubban ${ }^{15}$, Jayesh Dobariya ${ }^{16}$, Vikas Marwah ${ }^{17}$, Inder Sehgal ${ }^{18}$, Sameer Arvind Jog ${ }^{19}$, Atul Prabhakar Kulkarni ${ }^{20}$

\begin{abstract}
A. ACUTE HYPERCAPNIC RESPIRATORY FAILURE A1. Acute Exacerbation of COPD: Recommendations: NIV should be used in management of acute exacerbation of COPD in patients with acute or acute-on-chronic respiratory acidosis ( $\mathrm{pH}=7.25-7.35)$. (1A) NIV should be attempted in patients with acute exacerbation of COPD ( $\mathrm{pH}<7.25$ \& PaCO2 $\geq 45)$ before initiating invasive mechanical ventilation (IMV) except in patients requiring immediate intubation. (2A). Lower the $\mathrm{pH}$ higher the chance of failure of NIV. (2B) NIV should not to be used routinely in normo- or mildly hyper-capneic patients with acute exacerbation of COPD, without acidosis (pH > 7.35). (2B) A2. NIV in ARF due to Chest wall deformities/ Neuromuscular diseases: Recommendations: NIV may be used in patients of ARF due to chest wall deformity/Neuromuscular diseases. (PaCO2 2 45) (UPP) A3. NIV in ARF due to Obesity hypoventilation syndrome (OHS): Recommendations: NIV may be used in AHRF in OHS patients when they present with acute hypercapnic or acute on chronic respiratory failure (pH 45). (3B) NIV/CPAP may be used in obese, hypercapnic patients with OHS and/or right heart failure in the absence of acidosis. (UPP) B. NIV IN ACUTE HYPOXEMIC RESPIRATORY FAILURE: B1. NIV in Acute Cardiogenic Pulmonary Oedema: Recommendations: NIV is recommended in hospital patients with ARF, due to Cardiogenic pulmonary edema. (1A). NIV should be used in patients with acute heart failure/ cardiogenic pulmonary edema, right from emergency department itself. (1B) Both CPAP and BiPAP modes are safe and effective in patients with cardiogenic pulmonary edema. (1A). However, BPAP (NIV-PS) should be preferred in cardiogenic pulmonary edema with hypercapnia. (3A) B2. NIV in acute hypoxemic respiratory failure: Recommendations: NIV may be used over conventional oxygen therapy in mild early acute hypoxemic respiratory failure (P/F ratio $<300$ and $>200 \mathrm{mmHg})$, under close supervision. (2B) We strongly recommend against a trial of NIV in patients with acute hypoxemic failure with $P / F$ ratio $<150$. $(2 A) B 3$. NIV in ARF due to Chest Trauma: Recommendations: NIV may be used in traumatic flail chest along with adequate pain relief. (3B) B4. NIV in Immunocompromised Host: Recommendations: In Immunocompromised patients with early ARF, we may consider NIV over conventional oxygen. (2B). B5. NIV in Palliative Care: Recommendations: We strongly recommend use of NIV for reducing dyspnea in palliative care setting. (2A) B6. NIV in post-operative cases: Recommendations: NIV should be used in patients with post-operative acute respiratory failure. (2A) B6a. NIV in abdominal surgery: Recommendations: NIV may be used in patients with ARF following abdominal surgeries. (2A) B6b. NIV in bariatric surgery: Recommendations: NIV may be used in post-bariatric surgery patients with pre-existent OSA or OHS. (3A) B6c. NIV in Thoracic surgery: Recommendations: In cardiothoracic surgeries, use of NIV is recommended post operatively for acute respiratory failure to improve oxygenation and reduce chance of reintubation. (2A) NIV should not be used in patients undergoing esophageal surgery. (UPP) B6d. NIV in post lung transplant: Recommendations: NIV may be used for shortening weaning time and to avoid re-intubation following lung transplantation. (2B) B7. NIV during Procedures (ETI/Bronchoscopy/TEE/Endoscopy): Recommendations: NIV may be used for pre-oxygenation before intubation. (2B) NIV with appropriate interface may be used in patients of ARF during Bronchoscopy/Endoscopy to improve oxygenation. (3B) B8. NIV in Viral Pneumonitis ARDS: Recommendations: NIV cannot be considered as a treatment of choice for patients with acute respiratory failure with H1N1 pneumonia. However, it may be reasonable to use NIV in selected patients with single organ involvement, in a strictly controlled environment with close monitoring. (2B) B9. NIV and Acute exacerbation of Pulmonary Tuberculosis: Recommendations: Careful use of NIV in patients with acute Tuberculosis may be considered, with effective infection control precautions to prevent air-borne transmission. (3B) B10. NIV after planned extubation in high risk patients: Recommendation: We recommend that NIV may be used to wean high risk patients from invasive mechanical ventilation as it reduces re-intubation rate. (2B) B11. NIV for respiratory distress post extubation: Recommendations: We recommend that NIV therapy should not be used to manage respiratory distress post-extubation in high risk patients. (2B) C. APPLICATION OF NIV: Recommendation: Choice of mode should be mainly decided by factors like disease etiology and severity, the breathing effort by the patient and the operator familiarity and experience. (UPP) We suggest using flow trigger over pressure triggering in assisted modes, as it provides better patient ventilator synchrony. Especially in COPD patients, flow triggering has been found to benefit auto PEEP. (3B) D. MANAGEMENT OF PATIENT ON NIV: D1. Sedation: Recommendations: A non-pharmacological approach to calm the patient (Reassuring the patient, proper environment) should always be tried before administrating sedatives. (UPP) In patients on NIV, sedation may be used with extremely close monitoring and only in an ICU setting with lookout for signs of NIV failure. (UPP) E. EQUIPMENT: Recommendations: We recommend that portable bilevel ventilators or specifically designed ICU ventilators with non-invasive mode should be used for delivering Non-invasive ventilation in critically ill patients. (UPP) Both critical care ventilators with leak compensation and bi-level ventilators have been equally effective in decreasing the WOB, RR, and PaCO2. (3B) Currently, Oronasal mask is the most preferred interface for non-invasive ventilation for acute respiratory failure. (3B) F. WEANING: Recommendations: We recommend that weaning from NIV may be done by a standardized protocol driven approach of the unit. (2B)
\end{abstract}

Keywords: Acute respiratory failure, Chronic obstructive pulmonary disease, Guidelines, ICU, Mechanical ventilation, Non invasive ventilation. Indian Journal of Critical Care Medicine (2020): 10.5005/jp-journals-10071-G23186

\footnotetext{
(c) The Author(s). 2020 Open Access This article is distributed under the terms of the Creative Commons Attribution 4.0 International License (https://creativecommons. org/licenses/by-nc/4.0/), which permits unrestricted use, distribution, and non-commercial reproduction in any medium, provided you give appropriate credit to the original author(s) and the source, provide a link to the Creative Commons license, and indicate if changes were made. The Creative Commons Public Domain Dedication waiver (http://creativecommons.org/publicdomain/zero/1.0/) applies to the data made available in this article, unless otherwise stated.
} 


\section{INTRODUCTION}

The term non-invasive ventilation (NIV) refers to the application of ventilation without any conduit access to the airways i.e, without an endotracheal or tracheostomy tube. ${ }^{1}$ NIV has been used for over 25 years for the treatment of respiratory failure with indications for its use ever expanding and list of contraindications decreasing. ${ }^{2-8}$ Use of NIV leads to avoidance of endotracheal intubation (ETI). Hence, it decreases the incidence of ETI-associated complications like hospital acquired pneumonia (26\%) and sinusitis (7- 40\%). ${ }^{9-15}$ The Indian Society of Critical Medicine published NIV guidelines few years ago which needed to be updated in view of the availability of more evidence. ${ }^{1,8}$

\section{Materials and Methods}

This document is an expert consensus based guidelines for the use of NIV in the management of acute respiratory failure (ARF) in various disease states based on the available current literature. A systemic search was performed of MEDLINE, PUBMED and EMBASE databases using the search terms NIV, NIMV, NIPPV and disease name. We limited our search to English articles. The articles were divided into RCTs, systemic reviews, meta-analysis, case series and case reports. The expert group meeting was convened under the aegis of Indian Society of Critical Care Medicine at Pune. The expert group included intensivists from all over India. The evidence on each question was presented and deliberated. Recommendations were formulated and graded according to previous evidence based guidelines of ISCCM ${ }^{16}$ (Table 1). When there was no evidence, the recommendations were named as Useful Practice Point (UPP)
Corresponding Author: Subhal B Dixit, Department of Critical Care, Sanjeevan \& MJM Hospital, Pune, Maharashtra, India, Phone: 9822050240, e-mail: subhaldixit@yahoo.com

How to cite this article: Chawla R, Dixit SB, Zirpe KG, Chaudhry D, Khilnani GC, Mehta Y, et al. ISCCM Guidelines for the Use of Noninvasive Ventilation in Acute Respiratory Failure in Adult ICUs. Indian J Crit Care Med 2020;24(Suppl 1):S61-S81.

Source of support: Nil

Conflict of interest: None

\section{INDICATIONS FOR USING NIV}

The indications for the use of NIV have come to encompass a large and diverse number of clinical situations (Table 2).

\section{Acute Hypercapnic Respiratory Failure NIV in Acute Exacerbation of COPD}

Almost a quarter of COPD patients who come to hospital develop ARF over the course of their hospitalization. ${ }^{17,18}$ The presence of ARF is an independent risk factor for death in these patients. ${ }^{19}$ NIV has been used in COPD for more than two decades and has both preventive and therapeutic implications. ${ }^{20-46}$ There are numerous, randomized controlled trials, meta-analyses and case series conducted in these patients, which have demonstrated the efficacy of NIV in acute exacerbation of COPD.

NIV has been used in these patients i) to prevent the development of acute respiratory acidosis (Patients with normal or raised $\mathrm{PaCO} 2$, Normal $\mathrm{pH}$ ) or ii) to prevent use of invasive mechanical

Table 1: Criteria for quality of evidence levels and grading of strength of recommendations used in formulation of current guidelines

\begin{tabular}{|c|c|c|c|c|}
\hline \multicolumn{4}{|c|}{ Quality of Evidence } & Level \\
\hline \multicolumn{4}{|c|}{ Evidence from $\geq 1$ good quality and well conducted randomized control trial(s) or meta-analysis of RCT's } & 1 \\
\hline \multicolumn{4}{|c|}{$\begin{array}{l}\text { Evidence from at least } 1 \mathrm{RCT} \text { of moderate quality, or well-designed clinical trial without randomization; or from cohort } \\
\text { or case-controlled studies. }\end{array}$} & 2 \\
\hline \multicolumn{4}{|c|}{$\begin{array}{l}\text { Evidence from descriptive studies, or reports of expert committees, or opinion of respected authorities based on clinical } \\
\text { experience }\end{array}$} & 3 \\
\hline \multicolumn{4}{|c|}{$\begin{array}{l}\text { Not backed by sufficient evidence; however, a consensus reached by the working group, based on clinical experience } \\
\text { and expertise }\end{array}$} & (UPP) \\
\hline \multicolumn{4}{|c|}{ Strength of Recommendations } & Grade \\
\hline \multicolumn{4}{|c|}{$\begin{array}{l}\text { Strong Recommendations to do (or not to do) where the benefits clearly outweigh the risk (or vice versa) for most, if not } \\
\text { all patients }\end{array}$} & A \\
\hline \multicolumn{4}{|c|}{ Weak Recommendations, where benefits and risk are more closely balanced or are more uncertain } & B \\
\hline \multicolumn{5}{|c|}{ UPP, useful practice point; RCT, randomized controlled trial } \\
\hline Sr. No. & Acute Hypercapnic Respiratory Failure & Acute Hypoxemic Respiratory Failure & \multicolumn{2}{|c|}{ Special Conditions } \\
\hline 1. & $\begin{array}{l}\text { Acute exacerbation of Chronic Obstructive } \\
\text { Pulmonary disease }\end{array}$ & $\begin{array}{l}\text { Acute Cardiogenic Pulmonary } \\
\text { Edema }\end{array}$ & \multicolumn{2}{|l|}{ Post-Extubation } \\
\hline 2. & Acute Asthma & ARDS & \multicolumn{2}{|c|}{ Weaning in progress } \\
\hline 3. & Acute Exacerbation of Bronchiectasis & Pneumonia & \multicolumn{2}{|c|}{ Pre/Post Operative } \\
\hline 4. & $\begin{array}{l}\text { Acute Decompensation in Obesity Hypoventilation } \\
\text { Syndrome }\end{array}$ & $\begin{array}{l}\text { Multifactorial ARF in Immunicom- } \\
\text { promised patients }\end{array}$ & \multicolumn{2}{|c|}{ Palliative or Comfort Care } \\
\hline 5. & \multicolumn{2}{|l|}{ Acute Decompensation in Neuromuscular Disease } & \multicolumn{2}{|l|}{ Chest Trauma } \\
\hline 6. & \multicolumn{2}{|l|}{ Chest wall deformity } & \multicolumn{2}{|c|}{ NIV during procedures } \\
\hline
\end{tabular}


ventilation (IMV) [mild to moderate Acute respiratory acidosis $(\mathrm{pH}$ 7.25- 7.35) + respiratory distress ( $\mathrm{PaCO} 2>45)]$, and iii) therapeutically as an alternative to IMV in patients having severe acidosis $(\mathrm{pH}<7.25)$ and very severe respiratory distress.NIV should be used in these patients in addition to standard medical therapy. ${ }^{2-8}$

In a review of 17 RCTs involving a total of 1264 patients of AECOPD with ARF, Osadnik et al, reported that NIV decreased i) the risk of mortality (by almost half),ii) need for invasive mechanical ventilation (IMV) following endotracheal intubation (ETI)(by 65\%),iii) Length of Stay (LOS) in hospital (by almost 3 and half days), iv) incidence of complications (other than those related to NIV). ${ }^{44}$ Use of NIV also lead to improvement in biochemical parameters within an hour-increase in $\mathrm{pH}$ (by 0.05) and Oxygenation (by $7.47 \mathrm{mmHg}$ ) and a reduction in Carbon dioxide (by $4.62 \mathrm{mmHg}$ ). ${ }^{44}$ Keenan et al performed a meta-analysis of 15 RCTs in patients with AECOPD with ARF of varying severity. NIV reduced the need for IMV (in almost $30 \%$ of patients), hospital LOS (by 4 and half days) and mortality (by $10 \%)^{47}$

\section{NIV in AECOPD with Acute hypercapneic respiratory failure and acidosis ( $p H$ 7.25-7.35) to prevent ETI and IMV}

Use of NIV in this clinical setting has been demonstrated to have maximum beneficial effect. ${ }^{20-45}$ There is improvement in both $\mathrm{pH}$ as well as breathing, usually within an hour. ${ }^{48} \mathrm{NIV}$ improves clinical sense of well-being in patients and mortality rates, reduces rates of $\mathrm{ETI} /$ respiratory and non-respiratory infections and reduces hospital and ICU LOS. ${ }^{49-50}$

NIV in AECOPD with ARF with no or very mild acidosis

In an analysis of the subgroup of patients with mild exacerbation of AECOPD with ARF (PaCO2 $>=45 \mathrm{mmHg}, \mathrm{pH}>7.35$ ), Keenan et al demonstrated that the use of NIV was not beneficial. ${ }^{47} \mathrm{~A}$ subsequent RCT conducted by Keenan et al, in 52 patients with AECOPD without acidosis, comparing use of NIV plus standard therapy versus standard treatment alone showed poor tolerance of NIV and no benefit of use of NIV (no improvement in mortality on using IMV). ${ }^{20}$ In a previous small study (24 patients) on use of NIV in COPD patients with mild exacerbations (none of the patients required IMV or died), Barbe et al found no improvement in the Borg dyspnea score in patients who were given NIV. $30 \%$ of patients did not tolerate NIV. ${ }^{21}$ Another RCT as well as an observational study showed similar findings (poor intolerance and no benefit in terms of mortality or use of IMV in patients with AECOPD and mild or no acidosis. $^{22,23}$

NIV in AECOPD with Acute hypercapneic respiratory failure with severe acidosis $(p H<7.20)$

These patients usually require immediate ETI and IMV. Conti et al demonstrated that NIV was superior to IMV even in this setting. ${ }^{33}$ Patients who were ventilated noninvasively had lesser ICU and hospital LOS, infections and other complications. But there was no benefit in terms of survival. Both set of patients (ventilated invasively or non-invasively) demonstrated a similar mortality rate. Another RCT also demonstrated similar results. IMV was beneficial in rapid improvement in sensorium but had longer duration of ventilator use and ICU LOS. ${ }^{36}$ NIV was associated with fewer respiratory infections and tracheostomies. There was no difference in mortality rates in the two set of patients. ${ }^{36}$

Some patients require immediate ETI and IMV and NIV should not be implemented in these patients, e.g. - respiratory arrest, delirium requiring sedation, bradycardia ( $\mathrm{HR}<60$ per minute)and hypotension (MAP $<60 \mathrm{mmHg}$ ). ${ }^{33}$ NIV is not contraindicated in patients with coma due to high $\mathrm{CO} 2$ levels. In a large case series,
Diaz et al showed that NIV can be used in hypercapneic comatose patients with AECOPD. ${ }^{51}$

\section{Recommendations}

NIV should be used in the management of acute exacerbation of COPD in patients with acute or acute-on-chronic respiratory acidosis ( $\mathrm{pH}=7.25-7.35)$. (1A)

NIV should be attempted in patients with acute exacerbation of COPD ( $\mathrm{pH}<7.25 \& \mathrm{PaCO} 2 \geq 45$ ) before initiating invasive mechanical ventilation (IMV) except in patients requiring immediate intubation (2A). Lower the $\mathrm{pH}$, higher the chance of failure of NIV. (2B)

NIV should not be used routinely in normo- or mildly hypercapneic patients with acute exacerbation of COPD, without acidosis ( $\mathrm{pH}>7.35)$. (2B)

\section{NIV in ARF due to Chest wall deformities/Neuromuscular diseases}

There are no RCTs which compare NIV and IMV in these patients subsets.There are few studies with a small number of patients. ${ }^{52-54}$ Patients with kyphoscoliosis and neuromuscular diseases who present with Acute hypercapnic respiratory failure benefit from the use of NIV. There is improvement in gas exchange and ETI may be avoided.

\section{Recommendations}

NIV may be used in patients of ARF due to chest wall deformity/ Neuromuscular diseases. ( $\mathrm{PaCO} 2 \geq 45$ ) (UPP)

\section{NIV in ARF due to Obesity hypoventilation syndrome (OHS)}

NIV (Bilevel) or CPAP have both been used in patients with OHS and acute or chronic respiratory failure. ${ }^{55-56}$ Patients with OHS and ARF present with acidosis should be treated with bilevel NIV. There are no RCTs on the use of NIV/CPAP in these patients. Carillo et al prospectively studied the application of NIV in 173 patients with $\mathrm{OHS}$ and 543 patients with COPD. ${ }^{45}$ They found that patients with OHS and ARF could be managed with NIV as effectively and with better outcomes than COPD patients managed with a similar NIV protocol.

\section{Recommendations}

NIV may be used in Acute Hypercapneic Respiratory Failure (AHRF) in $\mathrm{OHS}$ patients when they present with acute hypercapnic or acute on chronic respiratory failure $(\mathrm{pH}<7.35 \& \mathrm{PaCO} 2>45)$. (3B)

NIV/CPAP may be used in obese, hypercapnic patients with OHS and/or right heart failure in the absence of acidosis. (UPP)

\section{NIV in Acute Hypoxemic Respiratory Failure}

\section{NIV in Acute Cardiogenic Pulmonary Oedema}

The benefit of NIV in acute cardiogenic pulmonary edema (ACPE), was first described in 1930 by Barach and Poulton. ${ }^{57,58}$ Currently, the use of NIV has increased in pre-hospital, emergency room and ICU settings. Many randomised trials have evaluated the effectiveness of NIV in ACPE, and have found significant improvement in physiological parameters like (heart rate, RR, BP), and also cardiopulmonary indices (SV, CO, Cl, PCWP).$^{59}$ However, none have shown a mortality benefit. The 3 CPO trial is the largest multi-center, prospective randomized trial of use of NIV in ACPE; 
with 1069 patients. ${ }^{60}$ The trial demonstrated no difference in 7-day mortality, with the use of CPAP, BPAP or oxygen. However, use of NIV was shown to improve breathlessness, HR and acidosis.

A systemic review of 15 randomized controlled trials from 10 countries and 727 patients, showed significant reduction in in-hospital mortality and intubation with use of NIV in ACPE. ${ }^{61}$ The use of CPAP found a statistically significant reduction in in-hospital mortality, whereas use of BPAP led to a non-significant reduction in the same. There was no difference in outcomes with the use of CPAP or BPAP (included 219 patients). Another meta-analysis of 23 RCTs also demonstrated similar findings. ${ }^{62}$

A Cochrane database, of 2916 patients with ACPE, from 32 RCTs, showed significant reduced hospital mortality and intubation rates with use of NIV. ${ }^{63}$ In a multicentre prospective observational study, ACPE SIMEU study group found NIV to have high clinical effectiveness in treatment of ARF due to ACPE as compared to conventional $\mathrm{O} 2$ therapy. ${ }^{64}$

\section{Recommendations}

NIV is recommended in hospital patients with ARF, due to Cardiogenic pulmonary edema. (1A)

NIV should be used in patients with acute decompensated heart failure/ cardiogenic pulmonary edema, right from emergency department itself. (1B)

CPAP and BPAP are the two principal modes used in ACPE. Agarwal et al combined the data of all RCTs of CPAP vs BPAP in $A C P E$, and found that BPAP increased intubation rates, and probably hospital mortality. ${ }^{65}$ However, it was not statistically significant, and they concluded that more studies were needed to compare. When CPAP and BPAP were compared in the systemic review by Vital and Colleagues, CPAP had better efficacy, safety and cost effectiveness as compared to BPAP and was to be preferred in this situation. ${ }^{63}$

\section{Recommendations}

Both CPAP and BiPAP modes are safe and effective in patients with cardiogenic pulmonary edema. $(1 \mathrm{~A})$

However, BPAP (NIV-PS) should be preferred in cardiogenic pulmonary edema with hypercapnia. (3A)

Among the newer modes available, not much research is available to recommend their use in ACPE. In patients with ACPE, rapid introduction of Adaptive Support Ventilation (ASV) in the Emergency Room reduced the rate of intubation. ${ }^{66}$ Proportional Assist Ventilation (PAV) was also not found to be superior to CPAP with regard to tolerance and efficacy. ${ }^{67}$

\section{NIV in acute hypoxemic respiratory failure}

Initial studies failed to show any added benefit of NIV in ARDS, despite physiological rationale available with its use. ${ }^{68}$ However, by the end of the decade, a meta-analysis of 13 studies and 540 subjects, showed that use of NIV in ARDS was associated with $48 \%$ intubation rates, and thus, $50 \%$ patients benefitted without needing intubation. ${ }^{69}$ Further more studies proved this point. ${ }^{70,71}$ In 2013, an observational cohort study of 113 patients showed an intubation rate of $35 \%$ in non-ARDS hypoxemic respiratory failure and in mild ARDS. However, in patients with severe hypoxemia, (PaO2/FiO2 $<150$ ) $84 \%$ of the patients required intubation. ${ }^{70}$ These findings were supported by another observational study, which concluded that NIV is safe in mild ARDS. However, in moderate to severe ARDS, it should be used with caution. ${ }^{71}$ Also; additional factors like shock, high APACHE II scores, and low PAO2/FiO2 scores were associated with risk of NIV failure and mortality.

In a meta-analysis of 2017, including 11 randomised studies and 1480 patients of acute hypoxemic nonhypercapenic failure of varied etiology showed that the use of NIV significantly reduced intubation rates and hospital mortality. ${ }^{72}$ Subgroup analysis showed an advantage of helmet (as compared to face or nasal mask) and BPAP, (over the other modes) in reducing the ICU mortality. In the Lung Safe study, patients of ARDS with lower ratio of $\mathrm{PaO} 2$ to inspired oxygen (P/F) less than $150 \mathrm{mmHg}$, had been found to be associated with higher chances of NIV failure and increased mortality (36.2\% in NIV group vs $24.7 \%$ in invasive ventilation group). ${ }^{73}$

Bellani et al recently found that the use of NIV in moderate to severe ARDS may be associated with a worse ICU outcome than invasive mechanical ventilation. ${ }^{74}$ While mortality rate was low for patients who were successfully managed with NIV, patients who failed NIV had a high mortality. A recent pilot multicentre RCT of 200 subjects with pneumonia induced early mild ARDS; NIV did not appear to help in reducing the number of intubations, despite the improvement in the $\mathrm{PaO} 2 / \mathrm{FiO} 2$ ratio after 2 hours of NIV use. ${ }^{75}$

\section{Recommendations}

NIV may be used over conventional oxygen therapy in mild early acute hypoxemic respiratory failure $(\mathrm{P} / \mathrm{F}$ ratio $<300$ and $>200$ $\mathrm{mmHg}$ ), under close supervision. (2B)

We strongly recommend against a trial of NIV in patients with acute hypoxemic failure with $\mathrm{P} / \mathrm{F}$ ratio $<150$. $(2 \mathrm{~A})$

\section{NIV in ARF due to Chest Trauma}

There are 3 RCTs which deal with the use of NIV in patients with ARF due to chest trauma. ${ }^{76-78}$ These RCTs show evidence from a small number of patients (total 171 patient in the 3 RCTs). NIV when used in patients with chest trauma is beneficial (reduced infectious complications and ICU and hospital stay) when compared with use of high flow oxygen through a mask or ETI and invasive MV. ${ }^{76-78}$ Therefore, the British Thoracic Society guidelines gave low grade recommendations for the use of non-invasive ventilation in trauma patients. ${ }^{2}$ TheCanadian Critical Care Trials Group/Canadian Critical Care Society Non-invasive Ventilation Guidelines Group gave no recommendation for use of NIV in patients with chest trauma, due to lack of sufficient evidence. ${ }^{79}$

\section{Recommendations}

NIV may be used in traumatic flail chest along with adequate pain relief. (3B)

\section{NIV in Immunocompromised Host}

In 2001, a prospective randomised trial of 52 immunosuppressed patients with pneumonitis, fever and early hypoxemic respiratory failure, showed a significant reduction in intubation rates and improved likelihood of survival to hospital discharge, in patients with NIV. ${ }^{80}$ In a large retrospective cohort study of use of NIV for acute hypoxemic respiratory failure in 1614 cancer patients, concluded NIV failure as an independent risk factor for ICU mortality. ${ }^{81}$

A recent post hoc analysis, of Lung Safe study, revealed the tendency of increased NIV use in the immunocompromised host, 
and patients with NIV, had a $48 \%$ rate of intubation. ${ }^{82}$ However, then there were trials with conflicting results. In a multicentre randomised trial of 374 immunocompromised subjects, early NIV, compared with standard oxygen, was not associated with clinical benefits in mortality, ICU-acquired infections, duration of mechanical ventilation or length of ICU stay. ${ }^{83}$ Similarly, The Efraim multinational prospective cohort study of immunocompromised patients with acute hypoxemic respiratory failure, the initial choice of oxygenation and ventilation strategy (standard oxygen vs High Flow Nasal Cannula (HFNC) vs NIV vs NIV + HFNC) did not affect mortality. ${ }^{84}$

A meta-analysis published in 2017 by Huang et al showed that early use of NIV is effective in reducing short term mortality in selected immunocompromised patients with acute respiratory failure. ${ }^{85}$ A recent meta-analysis of RCTs by Zayed et al showed that use of NIV in immunocompromised with acute hypoxemic respiratory failure, was associated with a significant reduction in the rate of intubations. However, no significant difference in mortality or ICU acquired weakness was seen. ${ }^{86} \mathrm{~A}$ meta-analysis comparing invasive and non-invasive ventilation in immunocompromised patients, showed more benefits with use of NIV, with a significant reduction in in-hospital mortality and 30-day mortality. ${ }^{87}$

\section{Recommendation}

In Immunocompromised patients with early ARF, we may consider NIV over conventional oxygen. (2B)

\section{NIV in Palliative Care}

In a randomised feasibility trial, Nava and colleagues recruited 200 patients with solid tumours and acute respiratory failure and limited life expectancy. The study showed a clear decrease in Borg dyspnoea score in the NIV group, along with lower requirement of total dose of morphine in the first $48 \mathrm{hrs}$. Adverse events leading to NIV discontinuation were mainly related to mask intolerance and anxiety. ${ }^{88}$

\section{Recommendation}

We recommend use of NIV for reducing dyspnea in palliative care setting. (2A)

\section{NIV in post-operative cases}

Post-operative respiratory failure due to any surgery is a result of anaesthesia, postoperative pain, and diaphragmatic dysfunction associated with both thoracic and abdominal surgeries. Hypoxemic respiratory failure is a result of lung volume reduction and atelectasis while hypercapneic respiratory failure is due to muscle fatigue. ${ }^{89}$ Both CPAP or bilevel NPPV plays an important role in the post-operative period.NIV prevents further intubation, shortens time on mechanical ventilation, prevents nosocomial infections, and significant morbidity and mortality after surgery.

\section{Recommendations}

NIV should be used in patients with post-operative acute respiratory failure. (2A)

\section{NIV in abdominal surgery}

A multicentre RCT published by Jaber et al included 298 patients with hypoxemic respiratory failure post abdominal surgery. It compared use of NIV versus standard oxygen therapy.NIV reduced risk of ventilator associated pneumonia ( $31 \%$ versus $49 \% ; \mathrm{P}=0.003$ ) and reduced risk of reintubation within 7 days $(46 \%$ versus $33 \%$; $=$ 0.03). ${ }^{90}$ In another prospective observational study, Jaber et al showed that NIV use in this situation avoided reintubation in $67 \%$ and improved mortality by reducing hospital stay. ${ }^{91}$ Ferreyra et al in their meta-analysis of 9 RCTs found that CPAP reduced pulmonary complications (atelectasis, pneumonia) in patients undergoing abdominal surgery. ${ }^{92}$

\section{Recommendations}

NIV may be used in patients with ARF following abdominal surgeries. (2A)

\section{Role of NIV in bariatric surgery}

Obesity is a significant risk factor for developing obstructive sleep apnoea (OSA). Approximately 27 to $70 \%$ of patients undergoing bariatric surgery show co-existence of OSA. ${ }^{93-95}$ Kaw et al explained that patients with obesity hypoventilation syndrome with or without OSA are more likely to develop post-operative complications including respiratory failure. There was a resultant increase in the use of NIV in post-operative condition to overcome OSA or OHS.

Both Gaszynski et al and Pessoa et al have shown that noninvasive ventilation improves oxygenation in postoperative obese patients. ${ }^{96,97}$ Wong et al compared the use of the CPAP mask with the standard air-entrainment mask and found improving oxygenation but no difference in postoperative \%FEV1 and \%FVC. ${ }^{98}$

In a large observational study of more than 5,000 patients with OSA and planned for bariatric surgery conducted by Stefan et al found that one out of five patients received NIV on the day of or the day after surgery. ${ }^{99}$ Early use of NIV in post-operative period did not improve outcomes, including chances of reintubation, mortality and hospital length of stay. Two single-centre retrospective cohort studies, one of patients undergoing Roux-en-Y bypass and the other of patients undergoing gastric banding surgeries, did not show any benefit of NIV in post-operative period. ${ }^{100,101}$ Systemic review of literature by Tong $S$ et al found no increased anastomotic dehiscence risk when NIV is administered during immediate postbariatric surgery. ${ }^{102}$

\section{Recommendations}

NIV may be used in post-bariatric surgery patients with pre-existent OSA or OHS. (3A)

\section{Role of NIV in Thoracic surgery}

In cardiothoracic surgeries deterioration of pulmonary function is a frequent postoperative complication and remains a significant cause of postoperative mortality. ${ }^{103}$ Impaired oxygenation is primarily attributed to a decrease in functional residual capacity in about $70 \%$ of patients post thoracotomy. ${ }^{104}$

In cases of Lung resection, NIV use in the post-operative period significantly reduced need of re intubation and reduced mortality as demonstrated in a RCT by Auriant et al. ${ }^{105}$ Stephan et al conducted a study in 830 post-cardiothoracic surgery patients with or at risk for respiratory failure. ${ }^{106}$ Use of high flow nasal cannula (HFNC) therapy was compared with intermittent NIV. It did not result in worse rate of treatment failure defined as need for reintubation. ${ }^{106}$ A metaanalysis of 14 trials by Zhu et al, included 1740 patients and showed 
that NIV had no significant effect in the treatment of patients after cardiothoracic surgery. But NIV improved oxygenation and reduced chances of reintubation. ${ }^{107}$

NIV in early oesophageal surgery is a relative contraindication for application of positive pressure at high level with risk of loss of integrity oesophageal sutures. ${ }^{108,109}$ A systematic review of literature conducted by Charlesworth et al could not find enough evidence for or against the use of NIV following oesophageal surgery. ${ }^{110}$

\section{Recommendations}

In cardiothoracic surgeries, use of NIV is recommended post operatively for acute respiratory failure to improve oxygenation and reduce chance of reintubation. (2A)

NIV should not be used in patients undergoing esophageal surgery. (UPP)

\section{Role of NIV in post lung transplant}

During post-operative period of lung transplant, graft and recipient -related respiratory difficulty requiring mechanical ventilation is a common scenario and can present within hours to days. Prolonged intubation in these immunocompromised patients is one of the main predisposing factors for developing nosocomial pneumonia, leading to prolonged ICU stay with significant morbidity and mortality. Non-invasive mechanical ventilation is recommended to shorten weaning time and to avoid reintubation following lung transplantation. ${ }^{111}$ -

\section{Recommendations}

NIV may be used for shortening weaning time and to avoid re-intubation following lung transplantation. (2B)

\section{NIV during Procedures (ETI/Bronchoscopy/TEE/Endoscopy)}

Patients with hypoxemic ARF may need to undergo various procedures for different indications. NIV decreases the rate of complications in patients undergoing bronchoscopy. In a small study (6 patients), Agarwal et al demonstrated that bronchoscopy can be safely performed in hypoxic patients with ARF. ${ }^{112}$ Two other studies also came to the same conclusion. ${ }^{113,114}$ In a retrospective study of 27 patients who underwent bronchoscopy under NIV support, Sircar et al demonstrated that it is feasible to perform bronchoscopy in hypoxemic patients, thus avoiding ETI. ${ }^{115}$

In an RCT, Baillard et al studied the effect of NIV for preoxygenation prior to ETI. Patients had better arterial oxygenation prior to and after intubation when preoxygenated with NIV as compared to non re-breather bag mask. ${ }^{116}$ In another multicentre RCT, Jaber et al used preoxygenation by NIV as a part of intubation protocol. ${ }^{117}$ These patients had lesser complications. Similar results were seen in an RCT involving morbidly obese patients undergoing ETI. ${ }^{118}$

\section{Recommendations}

NIV may be used for pre-oxygenation before intubation. (2B)

NIV with appropriate interface may be used in patients of ARF during Bronchoscopy/Endoscopy to improve oxygenation. (3B)

\section{NIV in Viral pneumonitis ARDS}

The role of NIV in acute respiratory failure, caused by H1N1 influenza has remained controversial. Initial studies did not recommend the use of NIV in H1N1 pneumonia. ${ }^{119,120,121}$ However, subsequent clinical experience and studies found good success rate with the use of NIV.

A Spanish registry of 148 patients with H1N1 pneumonia, NIV was used in 177 patients (25.8\%) with a success rate of $40.7 \%$. Low APACHE, low SOFA scores, no vasopressor requirement, absence of renal failure, fewer than 2 chest X-ray quadrant opacities were associated with NIV success. NIV success was associated with shorter hospital and ICU stay, and lesser mortality. ${ }^{122}$ Rodriguez et al did secondary analysis from prospective and observational multicentre trials of 1898 patients with hypoxemic respiratory failure due to influenza and found that NIV failure was $56.8 \%$. APACHE II score, SOFA score $\geq 5$ was associated with failure. ${ }^{123}$ Also, ICU mortality was higher in subjects with NIV failure, compared with invasive ventilation and NIV failure was associated with higher ICU mortality. A recent small cohort study of 43 patients of H1N1 pneumonia requiring NIV seconded the same findings and also found association of use of corticosteroids and early hemodynamic failure to be associated with NIV failure. ${ }^{124}$ Also they concluded that NIV failure was associated with increased mortality.

\section{Recommendations}

NIV cannot be considered as a treatment of choice for patients with acute respiratory failure with $\mathrm{H} 1 \mathrm{~N} 1$ pneumonia. However, it may be reasonable to use NIV in selected patients with single organ involvement, in a strictly controlled environment with close monitoring. (2B)

\section{NIV and Acute exacerbation of Pulmonary Tuberculosis}

NIV has been used for long term and domiciliary ventilations in patients with sequelae of pulmonary tuberculosis, and also for acute exacerbation of TB sequalae. ${ }^{125}$ However, its use in acute exacerbation of active pulmonary TB remains a controversial issue. Very few published reports and articles are available for the same. Agarwal et al reported 3 cases of successful treatment of tuberculous ARDS with NIV delivered with face mask. ${ }^{126}$ However, the main concern with use of NIV in TB is the potential risk of transmission of TB. Another concern is the prolonged need of NIV and higher risk of pneumothorax and haemoptysis.

\section{Recommendations}

Careful use of NIV in patients with acute Tuberculosis may be considered, with effective infection control precautions to prevent air-borne transmission. (3B)

\section{NIV after planned extubation in COPD patients}

Characteristic feature of COPD is persistent reduction in expiratory flow which is not fully reversible. It causes 'air trapping' and progressive hyperinflation of the lungs and flattening of the diaphragm. This leads to change in dynamics of the breathing precipitating chronic respiratory failure. As the disease progresses, patients are prone to experience exacerbations and frequent respiratory failure especially hypercapneic failure. Due to frequent infections, catabolic state with malnutrition and muscle wasting; 
COPD patients are difficult to wean from the invasive ventilation and have more chances to have extubation failure and reintubation. Nava et al. (2005) in their multicentre randomized controlled trial compared standard medical therapy versus immediate post-extubation NIV use in selected high-risk population for re-intubation. They found that, use of NIV in this population reduces the need for reintubation and significantly decrease in intensive care as well as in-hospital mortality. ${ }^{215}$ Khilnani et al. (2011), conducted a randomized controlled trial to study the effect of NIV immediately post extubation in COPD patients. ${ }^{216}$ They observed that there was less frequent need for reintubation in patients treated with NIV but ICU and in-hospital stay was same in both groups. In a multicentre randomized trial, C. Girault et al. (2011) investigated effectiveness of NIV as early weaning/ extubation technique in difficult to wean patients having chronic hypercapneic respiratory failure. ${ }^{217}$ They assigned patients in 3 groups; conventional weaning on invasive ventilation, extubation followed by standard oxygen therapy and extubation to NIV. They found that weaning failure rate along with post-extubation acute respiratory failure rate were significantly less in the NIV group.In Cochrane systematic review, Burnset al. studied trials comparing extubation followed by immediate NIV to continued invasive weaning on mechanical ventilation. ${ }^{218}$ They included 16 studies with 994 patients and interpreted that weaning to NIV reduces rate of death and pneumonia without increasing risk of weaning failure and reintubation. Mortality benefits were significantly greater in COPD patients in comparison to other subgroup population. ${ }^{218}$

\section{High Risk Patients ${ }^{215}$}

- More than one consecutive failure of weaning trial

- Chronic heart failure

- $\mathrm{PaCO} 2>45 \mathrm{~mm} \mathrm{Hg}$ after extubation

- More than one co-morbidity (excluding chronic heart failure).

- Weak cough defined as Airway Care Score values $\geq 8$ and $<12$

- Upper airways stridor at extubation not requiring immediate reintubation.

\section{Recommendation}

We recommend that NIV may be used to wean high risk patients from invasive mechanical ventilation as it reduces re-intubation rate. (2B)

\section{NIV for respiratory distress post extubation:}

Post extubation respiratory failure is one of the dreaded complications requiring reintubation, more chances of developing pneumonia, prolonged ICU stay and even have high mortality rate. There are many underlying reasons for the development of respiratory failure post extubation, of which unresolved primary condition, multiple comorbidities, development of pneumonia, and dependency on mechanical ventilation are a few common causes.

Esteban et al. conducted multicentre randomized controlled trial to the evaluate role of NIV in respiratory failure post extubation. The trial was stopped early after the interim analysis showed no difference in the rate of reintubation but there was increased intensive care mortality in NIV group as compared to standard medical treatment. ${ }^{219}$

Keenan et al (2002) conducted a randomized controlled trial to determine the role of NIV in preventing the need for reintubation in high risk patients developing respiratory failure post 48 hours of extubation. There was no difference in the rate of reintubation or hospital mortality in both groups. ${ }^{220}$

Meta-analysis done by Changyang Lin et al (2014) studied 10 trials involving 1382 patients. They observed that NIV in established respiratory failure post extubation did not decrease the reintubation rate and ICU mortality compared to standard medical therapy. ${ }^{221}$

\section{Recommendations}

We recommend that NIV therapy should not be used to manage respiratory distress post-extubation in high risk patients. (2B)

\section{Contraindications of NIV}

Most contraindications have been determined by the fact that they were the exclusion criteria in many studies. ${ }^{127,128}$ (See Table 3)

\section{Predictors of NIV Failure}

Although use of NIV is safe, it needs careful observation to detect failure at the earliest. Various studies have evaluated the risk factors/ predictors of NIV failure.

Various studies have shown the following criteria for NIV failure: ${ }^{129,130}$

- High severity score of illness (APACHE II, SAPS II, SOFA scores)

- Older age

- Failure to improve after 1 hour on NIV

- Multiorgan involvement

- Premorbid status (inability to perform self care)

- Mean $\mathrm{pH}<7.25$, mean $\mathrm{PaCO} 2>=75 \mathrm{mmHg}$ after 2 hours of NIV initiation, in patients with hypercapnic failure.

- Difficult to identify the etiology of acute respiratory failure

Table 3: Clinical scenarios of Contraindications for the use of NIV

\begin{tabular}{lll}
\hline Sr. No. & \multicolumn{1}{c}{ Contraindications } & \multicolumn{1}{c}{ Examples } \\
\hline 1. & Inability to protect the airways & $\begin{array}{l}\text { Comatose patients, Cerebrovascular Accident (CVA) with bulbar involvement, Confused and } \\
\text { Agitated patients. } \\
\text { Uncontrolled Arrhythmia, Patient on very high doses of Inotropes or Vasopressors with presence } \\
\text { of shock. }\end{array}$ \\
3. & Hemodynamic instability & Facial abnormalities, Facial burns, Facial trauma, Facial anomaly. \\
4. & Severe Gl Symptoms & Severe Vomiting, Obstructed bowel, Severe Hematemesis. \\
5. & Massive Hemoptysis & \\
6. & Copious secretions & \\
7. & Post-cardiac Arrest & \\
\hline
\end{tabular}


- ARDS / pneumonia as the etiology

- $\mathrm{PaO} 2 / \mathrm{FiO} 2<150 \mathrm{mmHg}$

- Higher Tidal volume generation.

In patients with early ARDS, SAPS II $>34$ and the inability to improve $\mathrm{PaO} 2 / \mathrm{FiO} 2$ after $1 \mathrm{hr}$ of NPPV were predictors of failure. ${ }^{131}$ In a secondary analysis of a multicentre observational study of NIV in 806 patients of confirmed Influenza Infection, found high APACHE II and a SOFA score $>=5$ as a risk factor for NIV failure. ${ }^{132}$

Similarly, The Efraim multinational prospective cohort study of immunocompromised patients with acute hypoxemic respiratory failure, showed that it is difficult to identify the aetiology of respiratory failure as an important predictor of NIV failure. ${ }^{84}$

A prospective observational study of 62 patients, of de novo acute hypoxemic respiratory failure, showed that an expired tidal volume of more than $9.5 \mathrm{ml} / \mathrm{kg}$ of PBW, accurately predicts NIV failure. $^{133}$

In the post hoc analysis of RCT REVA study, Frat et al concluded that a PaO2/FiO2 below 200 and a high tidal volume $>9 \mathrm{ml} / \mathrm{kg}$ are strong predictors of NIV failure in patients with acute hypoxemic respiratory failure. ${ }^{134}$ Multivariate analyses of the recent multicentre randomised ENIVA trial concluded that high minute ventilation was a risk factor for NIV failure. ${ }^{79}$

Around 2015, a single centre cohort study, concluded that NIV failure was associated with increased ICU and hospital stay and an increased risk of in-hospital mortality. ${ }^{135}$ Rodriguez et al analysed the use of NIV in confirmed influenza infection and found that ICU mortality increased in patients with NIV failure. ${ }^{132}$

\section{Recommendation}

NIV failure is an independent risk factor for mortality, thus we recommend careful patient selection for initiating non-invasive ventilation. (UPP)

\section{Application of NIV}

\section{Modes of NIV}

\section{General Considerations}

With the advancement of NIV, more and more modalities are now available for ventilating the patients. Same modalities with different names exist in different machines, thus complicating the situation further.

NIV devices have 2 types of triggers- "flow based" and "pressure based". Minute ventilation, respiratory pattern, dynamic lung compliance and resistance and changes in end-expiratory lung volume were the same with the two triggering systems. ${ }^{136}$ Flow triggering has shorter trigger delays and better synchrony. ${ }^{136,137}$

In COPD, flow triggering has been found to reduce the autoPEEP and inspiratory effort during both PSV and A/C modes compared with pressure triggering. ${ }^{136}$

\section{Recommendation}

We suggest using flow trigger over pressure triggering in assisted modes, as it provides better patient ventilator synchrony. Especially in COPD patients, flow triggering has been found to benefit auto PEEP. (3B)

Ventilation delivered by Non Invasive ventilators is either volume targeted or pressure targeted. There is no specific difference in the efficacy of either modalities.
Volume targeted ventilation provides more assured tidal volumes, despite changing lung mechanics. However, these modes fail to compensate the air flow for patient's varying needs, and circuit leaks. They are not used routinely by most care givers. Pressure targeted ventilation assures better delivery of tidal volume in systems with leaks and helps improve patient comfort and synchrony, with patient controlled inspiratory flows. ${ }^{138}$ Recent availability of hybrid variety of modality 'Volume-targeted pressure ventilation', helps to combine the advantages of both. ${ }^{139}$ Both modalities of delivery have been equally efficacious in decrement of $\mathrm{CO}_{2}$ levels, with no difference in the intubation rates and hospital mortality in a chinese prospective randomised controlled trial of acute hypercapnic failure. ${ }^{140}$

\section{Recommendations}

Pressure-targeted modes are preferred over volume-targeted to deliver ventilation in presence of air leaks, as they help to maintain TV better. (3B)

In patients who need high pressures for chest inflation (restrictive disease, severe chest deformity, obese), volumecontrolled ventilation mode is more effective. (UPP)

Non-invasive ventilatory breaths may be either timed cycled, or flow-cycled. Presence of a large leak in the NIV, interferes with the flow cycling of the ventilator. Time cycled breaths have shown to provide better synchrony in presence of large leaks, as shown in lung model studies and small clinical studies. ${ }^{138,141}$

\section{Recommendation}

When large leaks are present, we recommend to switch over to pressure targetted modes with time cycling, to provide better synchrony (3B).

\section{Newer Modes}

Newer modes of NIV mainly are Average volume assured pressure support (AVAPS), Intelligent volume assured pressure support ventilation (iVAPS), Proportional assisted ventilation (PAV), Adaptive servo ventilation (ASV), And use of Neurally-adjusted ventilatory assist (NAVA).

\section{Average Volume Targeted Pressure Support (AVAPS)}

As compared to BPAP, BPAP with AVAPS have been shown to help rapid recovery of consciousness in patients with COPD and hypercapnic encephalopathy. ${ }^{142}$ However, a recent multicenter RCT failed to demonstrate any significant difference in $\mathrm{CO}_{2}$ levels, intubation or in-hospital mortality with the use of AVAPS as compared to PS mode in patients with acute hypercapnic respiratory failure. ${ }^{140}$ Another pilot study to evaluate the feasibility of AVAPS in patients with COPD and acute hypercapnic failure, concluded that AVAPS may be used in this group of patients, but predictors of failure included higher baseline APACHE II scores and non-significant improvement in $\mathrm{PaCO} 2$ in the first 2 hours of treatment. ${ }^{143}$ Another small Turkish study, of patients with acute hypercapnic respiratory failure, included 33 and 29 patients in AVAPS-S and BPAP-S group, found more reduction in $\mathrm{PaCO} 2$ levels in the AVAPS-S group, however, the course was same in both the groups. ${ }^{144}$ Similarly, in 50 super obese patients, there was no difference between AVAPS and NIV PS mode, in terms of daytime $\mathrm{PaCO}_{2}$ at 3 months, and day time quality of life and fat 
mass reduction. ${ }^{145}$ Selim et al reviewed 120 relevant articles and concluded that AVAPS when compared to ASV, was found to deliver more consistent minute ventilation and can be recommended for sleep related hypoventilation disorder. ${ }^{146}$

\section{Recommendations}

AVAPS may be tried in patients in selected acute hypercapnic failure patients, under close supervision (3B)

\section{Proportional assist ventilation (PAV)}

Proportional assist ventilation (PAV) is a newer mode that delivers assisted ventilation in proportion to patient effort. Studies have failed to prove any benefit in reducing intubation rates, hospital stay or mortality, however, they do report better patient comfort and patient-ventilator synchrony with the use of PAV with NIV, as compared to PS mode. ${ }^{147,148}$ A recent systemic review and metaanalysis of 14 RCTs with 931 subjects, failed to reveal enough evidence for use of NIV-PAV in critically ill adults. ${ }^{149}$

\section{Recommendation}

There is not enough evidence to support the use of NIV-PAV in acute setting over PS mode. (1A)

\section{Adaptive Servo Ventilation (ASV)}

Selim Bet al. reviewed 120 relevant articles and concluded that ASV may be used to treat central sleep apnoea syndromes as it provides a more steady breathing airflow pattern. ${ }^{146} \mathrm{~A}$ recent randomised trial, with 74 patients with AECOPD, found using NIV with ASV was equally successful as PSV. ${ }^{150}$

\section{Recommendation}

There is not enough evidence to support the use of NIV-ASV over PSV. (1A)

\section{Neurally adjusted ventilatory assist (NAVA)}

Neurally adjusted ventilatory assist (NAVA) is a novel ventilatory mode that utilizes the electrical activity of the diaphragm to pick up respiratory signals and deliver assistance in proportion to the patient's ventilatory requirement. ${ }^{151}$ In a systemic review of studies (9 studies - 96 subjects), comparing the use of PSV versus NAVA during NIV for acute respiratory failure, revealed a significantly higher asynchrony index and a $3.4 \%$ times higher risk of severe asynchrony with PSV. ${ }^{152}$ Similar findings were found in a randomised study of 40 subjects with AECOPD, showing better patient-ventilator synchrony with use of NIV-NAVA as compared to NIV-PS. ${ }^{153}$ However, there was no difference in the gas exchange, duration of NIV, length of hospital stay and rate of NIV failure.

\section{Recommendation}

Non-invasive NAVA with mask / helmet, may be used to improve patient ventilator synchrony in patients with acute respiratory failure, depending on its availability and operator familiarity (UPP).

\section{Management of Patient on NIV}

\section{Sedation}

A Cochrane review of 2014 on the role of NIV as a weaning strategy from invasive mechanical ventilation found only one study that used a standardised sedation protocol before or after initiation of NIV. ${ }^{154}$ Matsumoto et al retrospectively evaluated the role of sedation in agitated patients treated with NIV after an episode of acute respiratory failure. ${ }^{155}$ Of 3506 patients who received NIV, only $3.4 \%$ (81 patients with non-intubation code [DNI] and 39 non-DNI) were sedated either intermittently or by continuous infusion. Drugs used were Risperidone or haloperidol for intermittent use and dexmedetomidine, midazolam or propofol for continuous infusion, titrated as per RASS scores. The authors concluded that sedation is potentially useful to avoid NIV failure in both groups of patients (DNI and non- DNI). ${ }^{155}$ An international prospective, observational multicentre study involving 322 ICUs in 30 countries, found that analgesia and sedation, either individually or combined, were used only in $19.6 \%$ of patients during NIV. They found when used alone, sedatives and analgesics are safe. However, their simultaneous use was found to be associated with NIV failure. ${ }^{156}$

In post extubation patients, use of sedation and/ or analgesia to improve interface tolerance, was found to decrease the rate of NIV failure, hospital mortality and ICU LOS. ${ }^{157}$

Drugs which have been used in trials are dexmedetomidine, Propofol, Remifentanil, and have been found safe and effective to use. ${ }^{158,159,160}$

\section{Recommendations}

A non-pharmacological approach to calm the patient (Reassuring the patient, proper environment) should always be tried before administrating sedatives. (UPP)

In patients on NIV, sedation may be used with extremely close monitoring and only in an ICU setting with lookout for signs of NIV failure. (UPP)

Sedation in patients on NIV if used appropriately and with the correct precautions improves patient comfort and reduces chances of NIV failure. (3B)

No preference of any drug can be recommended specifically for use in patients with ARF on NIV. (3B)

\section{Discharge}

The discharge process for patients requiring long term noninvasive ventilation requires meticulous planning and execution to prevent re-admissions to the health care. The protocol should be individualised for every patient, with adequate training and education of the care givers. Also round the clock health care service should be available.

\section{Recommendation}

For patients needing long term home NIV, an individualized plan with a plan matrix should be organized, involving all concerned parties, with clearly defined roles. Education and training of the care giver, round the clock technical support, are the minimum pre-requisites before planning to discharge the patient on NIV. (UPP) 


\section{Transport}

Recent reports from the Australian Helicopter Medical services, involving 3018 missions, in which there were 106 cases of NIV therapy during the retrieval revealed that none of these patients died or were intubated en route. ${ }^{161}$ These results demonstrate the growing safety of NIV in interhospital transport using NIV in patients with ARF, key however being proper patient selection.

\section{Recommendations}

Inter-hospital and Intra-hospital transport of patients on NIV may be considered only if absolutely necessary. (3B)

\section{Infection transmission with NIV}

Experimental model studies have shown that the dispersion distance of exhaled air particles from patients on NIV via the ResMed Ultra Mirage Mask was $0.5 \mathrm{~mm}$, along the exhalation port. ${ }^{162}$ Another human-patient simulator (HPS) study, showed the maximum dispersion distance of approximately $0.95 \mathrm{~m}$ with different face masks, with a more diffuse dispersion with use of whisper swivel exhalation port. ${ }^{163}$

A clinical study evaluated the characteristics of droplet/ aerosol dispersion in 3 groups of subjects and concluded that NIV and chest physiotherapy are droplet (not aerosol generating procedures, producing droplets $>10 \mu \mathrm{m}$ in size, which fall out within 1 metre. Oxygen therapy did not increase the droplet count in any size range. Whereas, a nebuliser produces aerosols of small and medium size. ${ }^{164}$ Similarly, a retrospective case control study by $\mathrm{Yu}$ and colleagues, concluded that use of NIV was not a significant contributory factor for spreading of infectious agents during the SARS epidemic in China. ${ }^{165}$

When use of helmet and face mask as an interface were compared, on a human patient simulator model with mild lung injury, the use of helmet with good seal around the neck was found to have limited exhaled air leak and dispersion. ${ }^{166}$ While using nasal masks, air leakage also occurs through the mouth, besides the exhalation valve. ${ }^{167}$ Choosing the correct size of the interface, with the best fit helps minimise the unintended air leaks. Higher ventilator pressures increase the range of dispersion of exhaled air and amount of air leakage around the interface. ${ }^{163}$ Other measures which have been useful in reducing the risk of nosocomial transmission of infection with use of NIV include using a dual limb circuit. The bias flow in the single limb circuits, prevents re-breathing and increases circuit leaks, thus also increasing dispersion of infected particles in the air. ${ }^{162}$ Adding a viral-bacterial filter between the mask and exhalation port has also been found useful to prevent infectious transmission. However, the risk of frequent blockage of the filter with moist secretions makes its use difficult. ${ }^{168}$ However, pulmonary TB infective particles are 1- $5 \mu \mathrm{m}$ in diameter and spread throughout the room by air currents. Due to relatively long period of infectivity of $\mathrm{TB}$, until the diagnosis and at least 2 weeks after initiation of anti-TB treatment, such patients need to be isolated in negative pressure isolation rooms with HEPA filters and ultraviolet germicidal irradiation (UVGI). ${ }^{169}$

\section{Recommendations}

Apart from personal protective equipment (N95 mask, gown, gloves, eye protection) and hand hygiene, we recommend the following precautions to be taken when using NIV on a patient with infectious disease: (3 B)

- Minimise leaks in the circuit.

- Non-vented face mask, or a helmet - with the best fit to the facial contour.

- Secure the mask, prior to turning on the ventilator. Turn off the ventilator before removing the mask.

- A viral/bacterial filter (to filter particles $0.3 \mathrm{~mm}$ in size) at the outlet of the ventilator and also at the expiratory side of the circuit.

- Complete decontamination of the ventilator before use in other patients.

\section{Equipment for NiV and Maintenance of NIV EquipMENT}

\section{Ventilators}

Use of non-invasive ventilators peaked during the polio epidemic of the 1950s, when negative pressure non-invasive ventilation helped to improve survival. ${ }^{170}$ It was only after early 2000 s that the positive pressure non-invasive ventilators became popular in the acute care setting. ${ }^{171}$ Any ventilator, designed to compensate for air leaks, can be used for delivering non-invasive ventilation. Most old invasive critical care ventilators, failed to compensate for the leaks and hence were not suitable for delivering non-invasive ventilation. ${ }^{172}$ In current critical care non-invasive ventilators with leak compensation, dual limb circuits with segregation of inspiratory and expiratory gases are used. In bi-level ventilators, a single limb circuit, with a leak port which serves as a port for passive exhalation is used. "Intermediate" ventilators have more recently been developed, which have combined features of bi-level, home and ICU ventilators, with wider range of inspiratory and expiratory parameters and volume as well pressure targeted ventilation. ${ }^{173}$ A comparison of different ventilators used for delivering NIV is shown in Table 4.

Initial clinical studies, found no differences in the work of breathing, respiratory rate, minute ventilation or $\mathrm{PaCO} 2$ between a bi-level ventilator and a critical care ventilator, when similar pressure settings were used. ${ }^{174,175}$

\section{Recommendations}

We recommend that bilevel ventilators or specifically designed ICU ventilators with non-invasive mode should be used for delivering Non-invasive ventilation in critically ill patients. (UPP)

Both critical care ventilators with leak compensation and bi-level ventilators have been equally effective in decreasing the WOB, RR, and $\mathrm{PaCO} 2$. (3B)

The $\mathrm{CO} 2$ rebreathing is a major concern when using bilevel ventilators with a single limb for delivering non-invasive ventilation. Following methods may help reduce the $\mathrm{CO} 2$ rebreathing which include:

- Leak port for exhalation in the mask than in the circuit/hose. ${ }^{176}$

- Titration of the oxygen in the mask than at the ventilator end. Though this affects the $\mathrm{FiO} 2$ delivery negatively. ${ }^{177}$

- Higher expiratory pressure. ${ }^{178}$

- Use of an exhalation valve (but also increases expiratory resistance). ${ }^{179}$ 
ISCCM Guidelines for the Use of Non-invasive Ventilation in Acute Respiratory Failure in Adult ICUs

Table 4: Comparison between different ventilators used for the purpose of Non-Invasive Ventilation

\begin{tabular}{|c|c|c|c|}
\hline & Bilevel ventilators & Critical Care Ventilators & Intermediate non-invasive ventilators \\
\hline Gas Source & $\begin{array}{l}\text { Compressor / Electronic turbine } \\
\text { pump }\end{array}$ & High pressure Gas Source & $\begin{array}{l}\text { Compressor / Electronic turbine } \\
\text { pump }\end{array}$ \\
\hline Circuit & Single limb & Dual limb & Single/ Dual Limb \\
\hline Exhalation valve & $\begin{array}{l}\text { Passive exhalation valve (Whisper } \\
\text { Swivel) }\end{array}$ & Active exhalation valve & Active exhalation valve \\
\hline Type of ventilation & $\begin{array}{l}\text { Old models provided only pressure } \\
\text { targeted ventilation. Newer models } \\
\text { provide volume targeted ventilation } \\
\text { as well. }\end{array}$ & $\begin{array}{l}\text { Volume and pressure targeted } \\
\text { ventilation }\end{array}$ & $\begin{array}{l}\text { Volume and pressure targeted } \\
\text { ventilation }\end{array}$ \\
\hline Advantages & $\begin{array}{ll}\text { - } & \text { Portable. } \\
\text { - } & \text { Easy to use. } \\
\text { - } & \text { Most Home Ventilators }\end{array}$ & Predictable FiO2 delivery & Predictable FiO2 delivery \\
\hline Disadvantages & $\begin{array}{l}\text { - Unpredictable } \mathrm{FiO} 2 \text { delivery, as } \\
\text { lacks a blender. May fail in patients } \\
\text { with high } \mathrm{O} 2 \text { requirement. } \\
\text { Risk of rebreathing, due to single } \\
\text { limb. }\end{array}$ & $\begin{array}{l}\text { - Lack of leak compensation, affects } \\
\text { the smooth functioning. } \\
\text { - Newer ICU ventilators have "NIV } \\
\text { modes" with leak compensation }\end{array}$ & $\begin{array}{l}\text { Some have an incomplete dual limb } \\
\text { circuit, in which the expiratory limb } \\
\text { is only a short tube with a PEEP valve. } \\
\text { This has negative effects on } \\
\text { triggering and cycling. }\end{array}$ \\
\hline
\end{tabular}

\section{Recommendations}

It is advisable to have leak port in the mask rather than the hose in order to reduce re-breathing in single limb bi-level ventilators. (3A)

The expiratory pressure should be kept minimum $4 \mathrm{cms} \mathrm{H} 2 \mathrm{O}$ to prevent re-breathing. ( $3 \mathrm{~A})$

\section{Interface}

The NIV interfaces currently available are nasal mask/pillows, oronasal mask, total-face mask, mouthpiece, and helmet. Bench studies and computerised calculations have shown a massive difference in the internal volume and the effective dead space of the mask. ${ }^{180,181}$ However, clinical and physiological studies found no difference in terms of the effect of this dynamic dead space on the patient effort, arterial blood gases, gas exchange and minute ventilation. ${ }^{182}$ Helmet when used as an interface has shown to interfere with triggering and cycling off delays, this leading to patient ventilator dyssynchrony. ${ }^{183}$ But using higher pressures in the helmet abolished these delays. ${ }^{184}$ Also, a meta-analysis in 2016, did not show an increase in the PaCO2 levels in patients with hypercapneic respiratory failure. ${ }^{185}$

\section{Recommendations}

Interfaces used for NIV may be interchangeable in clinical practice provided; adjustments of the ventilatory device parameters are performed. (3B)

In an acute setting, the choice of interface is based on the patient tolerance, staff experience and the fit on the face based on facial features. However, nasal masks/ pillows and mouthpiece, are not preferred due to predominance of mouth breathing. Web based survey in Europe and North America, showed that oro-nasal mask was most commonly used, up to $70 \% .{ }^{186}$ Another study in Brazil, reported the predominant use of oronasal and total face masks. ${ }^{187}$

The recent use of helmet has shown to offer advantages like less down time, and better airway clearance and also allows patients to drink and communicate. A systemic review and meta-analysis of 11 randomised and case control studies, comprising 621 subjects showed lower intubation rates, lower hospital mortality and less complications with the use of helmet. ${ }^{185}$ This reduction in intubation rates was seen in both hypercapneic and hypoxemic patients, independent of the ventilatory mode used. Another meta-analysis showed similar benefits in terms of intubation rates and hospital mortality, in patients with hypoxemic non-hypercapneic acute respiratory failure. ${ }^{188} \mathrm{~A}$ recent $\mathrm{RCT}$ by Patel et al, of subjects with ARDS, use of helmet reduced intubation rates, improved ventilator free days and improved mortality, over the use of face mask, without increase in the interface associated complications. ${ }^{189}$ Thus helmet appears promising in patients requiring higher pressures, however, further training of the medical team is necessary before its use.

\section{Recommendations}

Currently, Oronasal mask is the most preferred interface for noninvasive ventilation for acute respiratory failure. (2A)

A major challenge for patient co-operation for use of NIV is improving the patient comfort and reducing the risk of skin breakdown and damage. Beginning of skin breakdown has been seen within only 24 hours of use of NIV. ${ }^{190}$ A simple and effective strategy to prevent skin damage is to leave enough space to allow 2 fingers to pass between the skin and interface. ${ }^{191} \mathrm{~A}$ small amount of air leak should be acceptable for the same. A study by Weng of 90 participants, showed the equal efficacy of hydrocolloid and polyurethane dressings in preventing facial pressure ulcers during use of NIV. ${ }^{192}$ In a small Chinese RCT of 60 patients, similar findings were confirmed. ${ }^{193}$ Bishopp et al showed significant reduction in the risk of developing grade 2 pressure ulceration, with the early, prophylactic use of hydrocolloid nasal dressing. ${ }^{194}$ The study was a quality improvement project and the findings were compared retrospectively to previous 12 months admission. A recent RCT of 152 patients, showed maximum efficacy with the application of hyper oxygenated fatty acids (HOFA) in prevention of NIV related pressure ulcers, as compared to adhesive thin and foam dressing. ${ }^{195}$ A recent meta-analysis of RCTs, consisting of 1260 patients, found use of hydrocolloid dressing to significantly decrease the incidence of facial pressure ulcers. ${ }^{196}$ 


\section{Recommendations}

All interfaces used should be made of soft material. Cushioning of skin in contact with the interface may be done with hydrocolloids, foam pad, or transparent dressing. (3A)

All patients on NIV should undergo periodic skin assessment of pressure points, every 4-6 hourly. (UPP)

\section{Humidification}

Heat Moisture exchanger (HME) and heated humidifiers $(\mathrm{HH})$ are used for providing humidification in patients on NIV. Use of HME has found to produce higher absolute humidity levels of the upper airway. ${ }^{197}$ However, use of HME has found to increase the WOB, rebreathing and $\mathrm{PaCO} 2$ levels. ${ }^{198} \mathrm{~A}$ survey of 15 hospitals, revealed that $\mathrm{HHs}$ are used more often with NIV. ${ }^{199}$ However, a recent multicentre RCT of 15 centres, 247 patients - found no significant difference between the use of $\mathrm{HME}$ and $\mathrm{HH}$ in regards to mucosal dryness, intubation rate, PaCO2, NIV duration, ICU and hospital LOS, or ICU mortality. ${ }^{200}$ This study though was underpowered. The risk associated with the use of $\mathrm{HME}$, is its frequent blockage with moist secretions, and the added resistance to breathing.

\section{Recommendation}

Humidification is routinely not required in patients on NIV. However, patients who complain of dryness of respiratory tract, or thick tenacious secretions, heated humidification or HME may be considered. (3B)

\section{Aerosol Delivery}

Use of aerosol is an integral part of therapy in COPD, asthma. Aerosol delivery is affected by leaks, inspiratory flow rates and position of expiratory port. Data is lacking to comment if use of nebulisers or MDI is better for aerosol delivery with NIV. The most favourable position for placement of the nebuliser for an optimal deposit is to put the nebulisation device between the interface and the respiratory circuit. ${ }^{201,202}$

\section{Recommendation}

We advise placing the nebuliser between the mask with/without expiratory port and the respiratory circuit. (3A)

\section{Cleaning and Disinfection of Accessories}

Cleaning, rinsing and drying of the equipment of NIV, is important to prevent cross-infection. Disposable parts should not be re-used.

\section{Recommendations}

We advise cleaning and disinfection of non-invasive ventilators and its accessories should be as per manufacturer's recommendations. The standard of care should be followed, and proper documentation maintained. (UPP)

\section{Practical Application}

\section{Initiation and Customisation}

\section{Assess the need of NIV}

Before application of Non-invasive ventilation, it is important to assess the need of NIV. In addition to the rest of the medical
Table 5: Clinical criteria

Moderate to severe respiratory distress

Tachypnea (respiratory rate $>25 / \mathrm{min}$ )

Accessory muscle use or abdominal paradox

Blood gas derangement $\mathrm{pH}<7.35, \mathrm{PaCO}_{2}>45 \mathrm{mmHg}$

$\mathrm{PaO}_{2} / \mathrm{FiO}_{2}<300$ or $\mathrm{SpO}_{2}<92 \%$ with $\mathrm{FiO}_{2} 0.5$

treatment, NIV should be applied simultaneously to a patient in acute respiratory failure (ARF), based on the clinical criteria (Table 5 ), provided there is no contraindication. NIV should only be considered if there is enough evidence of its effectiveness in that particular disease condition.

NIV is initiated mostly in the emergency department, intensive care unit and HDU. NIV has been found to be most effective in COPD. NIV should be initiated in COPD when $\mathrm{pH}<7.35$ and $\mathrm{pCO} 2>45$ $\mathrm{mmHg}$ persists or develop despite optimal medical therapy. Severe acidosis is not a contraindication to NIV so long as the expertise to perform safe endotracheal intubation is readily available. The lower the $\mathrm{pH}$ the more chances of failure. One should not delay intubation when it is indicated.

Current guidelines recommend CPAP or bilevel NIV for patients with ARF due to cardiogenic pulmonary edema. There is uncertainty of evidence to recommend the use of NIV for ARF due to asthma. NIV can be used for patients with post-operative ARF. NIV is recommended for dyspnoeic patients for palliation in the setting of advanced cancer or other terminal conditions.NIV has been applied for chest trauma patients with ARF with success. NIV is recommended to prevent post-extubation respiratory failure in high-risk patients. NIV should not be used in the treatment of patients with established post-extubation respiratory failure.

\section{Recommendations}

NIV therapy should be initiated for patients in Critically Monitored Area like ICU, HDU, ER, and Respiratory Wards with adequately trained staff. (UPP)

\section{Arterial blood gas ( $A B G)$}

ABG is usually used to judge the effectiveness of NIV especially in cases of Acute Hypercapneic Failure. ABG monitoring should be done within one hour after initiation of NIV therapy. Repeat Frequency should be based on the clinical condition of the patient, first ABG findings and NIV settings.

\section{Recommendations}

We recommend first ABG within first hour of NIV therapy. After this, the frequency should be based on clinical condition of patient. (UPP)

\section{Level of consciousness}

A severely altered level of consciousness especially in hypoxemic respiratory failure is considered to be a possible contraindication to non-invasive ventilation. To assess level of consciousness with the use of Glasgow Coma Scale (GCS), ability to cough out secretions and maintain airways are important to assess before and after application of NIV.

Mariko et al. in 2018 conducted a study on 237 patients on NIV, they divided the patients in two groups, one with normal level of consciousness (NLC) with GCS 15 and Altered level of 
consciousness (ALC) with GCS 14 or less, patients with GCS less or equal to 8 were excluded considering safety reasons and need for intubation, they also used Kelly-Matthay scale. ${ }^{203}$ Eighty-nine patients were excluded because of underlying respiratory disease $(n=74)$ and the need for urgent intubation $(n=15)$. Among the 148 included patients, 66 had ALC and 82 did not. They concluded that with careful monitoring and management NIV may be successfully applied in patients with mild ALC during episodes of hypoxemic respiratory failure.

Scala et al in 2005 did a case control study on eighty of 153 consecutive COPD patients requiring NIV for ARF which were divided into four groups depending on Kelly-Matthay scale. ${ }^{204}$ They confirmed that NIV may be successfully applied in patients with COPD exacerbations with milder ALCs, whereas the rate of failure in patients with severely ALCs (i.e., Kelly score > 3) is higher; even though better than expected, so that an initial and cautious attempt with NIV may be performed even in this latter group.

The Kelly-Matthay scale ranges from Grades 1 to 6 with Grade 1- alert, follows complex 3-step commands; Grade 2- alert, follows simple commands; Grade 3- lethargic, but arousable and follows simple commands; Grade 4- stuporous, only intermittently follows simple commands even with vigorous attempts at arousal; Grade 5 , comatose, brain stem intact; grade 6 , comatose with brainstem dysfunction. ${ }^{204,205}$

\section{Recommendation:}

We recommend that the consciousness level of the patient should be assessed with GCS. (2A)

\section{Delirium}

Charlesworth et al performed a systematic review and meta-analysis of the literature to determine the prevalence of delirium in patients on NIV and its impact on patients on NIV. They conclude that data related to this is scarce and of low quality. Though the data was of low quality, there was high reported prevalence of delirium and the association with NIV failure lends support for more awareness and more routine screening. ${ }^{206}$ Multinational survey conducted by Tanaka et al. in 2015 also strongly reemphasize poor efforts towards delirium assessment and management in the intensive care unit setting, especially regarding patients on NIV. ${ }^{207}$

\section{Recommendations}

We recommend delirium monitoring should be done with CAM-ICU score for NIV success. (UPP)

\section{Transcutaneous $\mathrm{CO}_{2}$}

Transcutaneous $\mathrm{CO}_{2}$ is a continuous pain-free monitoring of $\mathrm{CO}_{2}$ measurements and may replace the frequent need of $A B G s$ for $\mathrm{CO}_{2}$ measurement that is more painful, requires frequent puncture leading to technical expertise, bleeding, hematoma and is snapshot measurement

Retrospective analysis of Patients on NIV in Emergency Department done by Horvah et al., published in Swiss Medical Weekly on 26th October 2016, concluded that transcutaneous $\mathrm{PCO}_{2}$ monitoring shows a good concordance with $\mathrm{PaCO}_{2}$ and is a reliable, feasible, patient-friendly and safe alternative to repeated blood gas analysis for patients with severe hypoxaemic and/or hypercapneic respiratory failure receiving emergency NIV in the ED.
Table 6: Clinical criteria to be met by patients before Weaning is attempted.

\begin{tabular}{lll}
\hline S. No & \multicolumn{1}{c}{ Measure } & \multicolumn{1}{c}{ Character } \\
\hline 1. & Arterial pH & $\geq 7.35$ \\
2. & SpO2 & $>90 \%$ \\
3. & Respiratory Rate & $\leq 25 / \mathrm{min}$ \\
4. & Heart rate & $\leq 120 / \mathrm{min}$ \\
5. & Systolic blood pressure & $\geq 90 \mathrm{mmHg}$ \\
6. & Signs of respiratory & No agitation, diaphoresis, \\
& distress & anxiety
\end{tabular}

In addition, it can be used to adapt NIV settings in real time. An initial $A B G$ to evaluate the respiratory and metabolic state and to rule out a significant discrepancy compared with the transcutaneous measurement is recommended. ${ }^{208}$

One Pilot observational study concluded that continuous $\mathrm{PtcCO}_{2}$ monitoring provides a promising alternative to repeated blood sampling in subjects requiring NIV for acute hypercapneic respiratory failure. ${ }^{209}$

\section{Recommendations}

Transcutaneous $\mathrm{CO} 2$ may be used for monitoring patients of COPD in place of repeated $A B G$ monitoring. (2B)

\section{WEANING}

NIV reduces respiratory muscle fatigue and improves ventilation. Its usage has increased during acute settings. Sometimes, patients having COPD, OSA, various neuromuscular disorders including critical illness myoneuropathy require NIV for prolong period. Weaning from NIV in these patients is a difficult and tedious job. Weaning needs to be started only when primary condition is better, and patient meets the clinical criteria shown in Table $6 .^{210,211}$

\section{Protocol Based Weaning}

Protocol based weaning strategies have been found to be more successful with shorter duration of NIV requirement and shorter ICU length of stay.

Jun Duan et al in their prospective randomized control trial compared protocolized vs physician directed weaning from NIV. ${ }^{212}$ They formulated the protocol and randomized the patients in two groups. Respiratory technicians in Protocol- derived weaning group initiated the weaning attempt as per the protocol and in other group weaning was done as per the physicians' decision. They observed that protocol directed weaning significantly reduced the duration of NIV as well as length of stay in the ICU.

\section{Recommendations}

We recommend that weaning from NIV may be done by a standardized protocol driven approach of the unit. (2B)

\section{Weaning strategies}

Varied Strategies for weaning from NIV has been described:

- Stepwise reduction in NIV duration.

- Stepwise reduction in NIV pressure support.

- Immediate withdrawal of NIV after stabilization. 


\section{Strategy}

Stepwise reduction in NIV duration

This method involves progressively reducing the duration of NIV over a period of 3-4 days once the patient satisfies the criteria for weaning. Initially weaning should be carried during daytime with overnight ventilation. The daytime weaning can be divided into periods of 3 hours each and can be performed as follows - during first $24 \mathrm{hrs}$ in each 3 hours, one hour without NIV (except during night period), in the second day in each 3 hours, two hours without NIV (except during night period) and in the third day NIV can be used only during the night period. NIV may be discontinued on day 4 unless continuation is clinically indicated for example, few hours in daytime and six hours or more overnight. ${ }^{213}$

Plant et al used this strategy of stepwise reduction in NIV duration: On Day One, used as much of NIV, Day Two, NIV was used for 16 hours (including 6-8 hours of overnight NIV), On Day three, $12 \mathrm{hrs}$ of NIV (including 6-8 hours of overnight NIV) and discontinued on Day 4.

Recently published study by Venkatnarayan et al weaning from NIV used 16 hours of NIV (Including 6-8 hours of Overnight) on Day of randomization, Day 2: 12 Hours of NIV (Including 6-8 hours of Overnight) and Day 3: Only overnight NIV was used and complete withdrawal on Day 4. ${ }^{214}$

Stepwise reduction in NIV pressure support

This strategy involves gradual reduction $(2-3 \mathrm{cms}$ of $\mathrm{H} 20)$ of IPAP and EPAP over a period of $6-8 \mathrm{hrs}$ and removing NIV once the patient tolerates IPAP of $6-8 \mathrm{cms}$ of $\mathrm{H} 2 \mathrm{O}$ and EPAP of $4-5 \mathrm{cms}$ of H2O.There are no studies comparing the effectiveness of stepwise reduction of duration versus stepwise reduction of pressure support, but both the strategies can be used in conjunction with each other. ${ }^{211,214}$ Immediate withdrawal of NIV

This strategy involves immediate cessation of NIV once the patient stabilizes. Though it has potential advantage of shortening the duration of weaning process, the rates of failure of weaning and reinstitution of NIV can be higher. A randomized control trial by Lun et al compared immediate withdrawal of NIV to stepwise reduction and found success rate of weaning to be $56 \%$ and $74 \%$ respectively, although the data is statistically not significant. ${ }^{210}$ Immediate withdrawal of NIV can be tried in patients who required NIV for a shorter duration of time and who have clinically recovered well.

Venkatnarayan et al in 2019 compared above three strategies for weaning from NIV in patients with COPD with acute exacerbation and hypercapneic respiratory failure. ${ }^{214}$ They found that there was increased chance of weaning failure in immediate withdrawal group but without any statistically significant difference. Total duration of NIV use and length of stay was significantly less in group of immediate withdrawal and gradual reduction in pressure support group than stepwise reduction in NIV duration group.

\section{Recommendations}

We recommend that any of three weaning strategies may be adopted for weaning NIV in COPD patients. (2B)

\section{Conclusions}

Non-invasive ventilation has been recognised a very important modality in the management of acute respiratory failure. NIV should only be used if there is good quality evidence of its effectiveness in that particular condition and there is no contraindication. NIV can be used for patients with ARF due to COPD cardiogenic pulmonary, post-operative ARF, palliation in the setting of advanced cancer or other terminal conditions, chest trauma with ARF and to prevent post-extubation respiratory failure in high-risk patients. NIV should not be used in the treatment of patients with established post-extubation respiratory failure. It is important to fine-tune the patient, interface, and ventilator. NIV can be delivered via portable pressure ventilator or the standard ICU type of ventilator found in most intensive care units (ICUs). Pressure modes are preferred because there are many advantages of pressure targeted modes like pressure delivered is constant and pressure targeted ventilation compensates for air leak. Monitor continuously the patient on NIV for the worsening sensorium, respiratory distress, tachypnea, and deteriorating blood gases, and intervene early because delay in intubation worsens outcome. Most complications are minor that can be managed easily, and so every attempt should be made to continue NIV. Weaning can be done by various methods with equal efficacy. Protocol based weaning strategies have been found to be more successful with shorter duration of NIV requirement and shorter ICU length of stay.

\section{References}

1. Chawla R, Chaudhry D, Kansal S, Khilnani GC, Mani RK, Nasa P, et al. Guidelines for noninvasive ventilation in acute respiratory failure. Indian J Crit Care Med 2013;S1:42-70.

2. Davidson C, Banham S, Elliott M, Kennedy D, Gelder C, Glossop A, et al. British Thoracic Society Standards of Care Committee. Non-invasive ventilation in acute respiratory failure. Thorax 2002;57:192-211.

3. International Consensus Conferences in Intensive Care Medicine: Noninvasive Positive Pressure Ventilation in Acute respiratory Failure. Am J Respir Crit Care Med 2001;163:283-291.

4. Pingleton SK. Complications associated with mechanical ventilation. In: Tobin MJ (ed) Principles and Practice of Mechanical Ventilation. McGraw-Hill Inc, New York pp 1994;775-792.

5. Davidson AC, Banham S, Elliott M, Kennedy D, Gelder C, Glossop A, et al. BTS/ICS guideline for the ventilatory management of acute hypercapnic respiratory failure in adults. Thorax 2016;71:ii1-ii35.

6. Rochwerg B, Brochard L, Elliott MW, Hess D, Hill NS, Nava S, et al. Official ERS/ATS clinical practice guidelines: noninvasive ventilation for acute respiratory failure. Eur Respir J 2017;50:pii 1602426.

7. Demoule A, Chevret S, Carlucci A, Kouatchet A, Jaber S, Meziani F, et al. Changing use of noninvasive ventilation in critically ill patients: trends over 15 years in francophone countries. Intensive Care Med 2016;42(1):82-92.

8. Chawla R, Khilnani GC, Suri JC, Ramakrishnan N, Mani RK, Prayag $S$, et al. International Reviewer: Brochard Laurent. Guidelines for noninvasive ventilation in acute respiratory failure. Published 2005. https//:www.isccm.org Accessed 20/01/2020.

9. Torres A, Aznar R, Gatell JM, Jimenez P, Gonzalez J, Ferrer A, et al. Incidence, risk and prognosis factors of nosocomial, pneumonia in mechanically ventilated patients. Am Rev Respir Dis 1990;142:523528.

10. Craven DE, Kunches LM, Kilinsky V, Lichtenberg DA, Make BJ, McCabe WR. Risk factors for pneumonia and fatality in patients receiving mechanical ventilation. Am Rev Respir Dis 1986;133:792-796.

11. Fagon JY, Chastre J, Hance AJ, Montravers P, Novara A, Gibert C. Nosocomial pneumonia in ventilated patients: $A$ cohort study evaluating attributable morality and hospital stay. Am J Med 1993;94:281-282.

12. Violan JS, Sanchez-Ramirez C, Mujica AP, Cendrero JC, Fernandez JA, de Castro FR. Impact of nosocomial pneumonia on the outcome of mechanically-ventilated patients. Crit Care 1998;2:19-23.

13. van Zanten ARH, Dixon JM, Nipshagen MD, de Bree R, Girbes ARJ, Polderman $\mathrm{KH}$. Hospital-acquired sinusitis is a common cause of fever 
of unknown origin in orotracheally intubated critically ill patients. Crit Care 2005;9:R583-R590.

14. George DL, Falk PS, Umberto Meduri G, Leeper KV Jr, Wunderink $\mathrm{RG}$, Steere EL, et al. Nosocomial sinusitis in patients in the medical intensive care unit: a prospective epidemiological study. Clin Infect Dis 1998;27:463-470.

15. Agrafiotis, M, Vardakas, KZ, Gkegkes, ID, Kapaskelis, A, Falagas, ME. Ventilator-associated sinusitis in adults: systematic review and metaanalysis. Respir Med 2012;106(8):1082-1095.

16. Khilnani GC, Zirpe K, Hadda V, Mehta Y, Madan K, Kulkarni A, et al. Guidelines for Antibiotic Prescription in Intensive Care Unit. Indian J Crit Care Med 2019;23(Suppl 1): S1-S63.

17. Plant PK, Owen J, Elliott MW. One year period prevalence study of respiratory acidosis in acute exacerbation of COPD; implications for the provision of non-invasive ventilation and oxygen administration. Thorax 2000;55:550-554.

18. Roberts CM, Stone RA, Buckingham RJ, Pursey NA, Lowe $D$, et al. Acidosis, non-invasive ventilation and mortality in hospitalized COPD exacerbations. Thorax 2011;66:43-48.

19. Jeffrey AA, Warren PM, Flenley DC. Acute hypercapnic respiratory failure in patients with chronic obstructive lung disease: risk factors and use of guidelines for management. Thorax 1992;47:34-40.

20. Keenan SP, Powers CE, McCormack DG. Noninvasive positive-pressure ventilation in patients with milder chronic obstructive pulmonary disease exacerbations: a randomized controlled trial. Respir Care 2005;50:610-616.

21. Barbe F, Togores B, Rubi M, Pons S, Maimó A, Agustí AGN, et al. Noninvasive ventilatory support does not facilitate recovery from acute respiratory failure in chronic obstructive pulmonary disease. Eur Respir J 1996;9:1240-1245.

22. Bardi G, Pierotello R, Desideri M, Valdisserri L, Bottai M, Palla A. Nasal ventilation in COPD exacerbations: early and late results of a prospective, controlled study. Eur Respir J 2000;15:98-104.

23. Wood KA, Lewis L, Von Harz B, Kollef MH. The use of noninvasive positive pressure ventilation in the emergency department. Chest 1998;113:1339-1346.

24. Collaborative Research Group of Noninvasive Mechanical Ventilation for Chronic Obstructive Pulmonary Disease. Early use of non-invasive positive pressure ventilation for acute exacerbations of chronic obstructive pulmonary disease: a multicentre randomized controlled trial. Chin Med J 2005;118:2034-2040.

25. O'Driscoll BR, Howard LS, Davison AG. BTS guideline for emergency oxygen use in adult patients. Thorax 2008;63(6):vi1-vi68.

26. Austin MA, Wills KE, Blizzard L, Walters EH, Wood-Baker R. Effect of high flow oxygen on mortality in chronic obstructive pulmonary disease patients in prehospital setting: randomised controlled trial. BMJ 2010;341:C5462.

27. Angus RM, Ahmed AA, Fenwick LJ, Peacock AJ. Comparison of the acute effects on gas exchange of nasal ventilation and doxapram in exacerbations of chronic obstructive pulmonary disease. Thorax 1996;51:1048-1050.

28. Avdeev SN, Tretyakov AV, Grigoryants RA, Kutsenko MA, Chuchalin AG. Issledovanie primeneniia neinvazivnoi ventiliatsii legkikh pri ostroi dykhatel'noi nedostatochnosti na fone obostreniia khronicheskogo obstruktivnogo zabolevaniia legkik. [Study of the use of noninvasive ventilation of the lungs in acute respiratory insufficiency due exacerbation of chronic obstructive pulmonary disease.] Anesteziol Reanimatol 1998;3:45-51.

29. Bott J, Carroll MP, Conway JH, Keilty SE, Ward EM, Brown AM, et al. Randomised controlled trial of nasal ventilation in acute ventilatory failure due to chronic obstructive airways disease. Lancet 1993;341:1555-1557.

30. Brochard L, Mancebo J, Wysocki M, Lofaso F, Conti G, Rauss A, et al. Noninvasive ventilation for acute exacerbations of chronic obstructive pulmonary disease. N Engl J Med 1995;333:817-822.

31. Carrera M, Marin JM, Anton A, Chiner E, Alonso ML, Masa JF, et al. A controlled trial of noninvasive ventilation for chronic obstructive pulmonary disease exacerbations. J Crit Care 2009;24:473.e7-e14.
32. Celikel T, Sungur M, Ceyhan B, Karakurt S. Comparison of noninvasive positive pressure ventilation with standard medical therapy in hypercapnic acute respiratory failure. Chest 1998;114:1636-1642.

33. Conti G, Antonelli M, Navalesi P, Rocco M, Bufi M, Spadetta G, et al. Noninvasive vs. conventional mechanical ventilation in patients with chronic obstructive pulmonary disease after failure of medical treatment in the ward: a randomized trial. Intensive Care Med 2002;28:1701-1707.

34. del Castillo D, Barrot E, Laserna E, Otero R, Cayuela A, Castillo Gómez J. Ventilacion no invasiva por soporte de presion en pacientes con enfermedad pulmonar obstructiva cronica en insuficiencia respiratoria aguda hipercapnica ingresados en una unidad de hospitalizacion convencional de neumologia. [Noninvasive positive pressure ventilation for acute respiratory failure in chronic obstructive pulmonary disease in a general respiratory ward.] Med Clin 2003;120:647-651.

35. Dikensoy O, Ikidag B, Filiz A, Bayram N. Comparison of non-invasive ventilation and standard medical therapy in acute hypercapnic respiratory failure: a randomised controlled study at a tertiary health centre in SE Turkey. Int J Clin Pract 2002;56:85-88.

36. Jurjević M, Matić I, Sakić-Zdravcević K, Sakić S, Danić D, Buković D. Mechanical ventilation in chronic obstructive pulmonary disease patients, noninvasive vs. invasive method (randomized prospective study). Coll Antropol 2009;33:791-797.

37. Khilnani GC, Saikia N, Banga A, Sharma SK. Non-invasive ventilation for acute exacerbation of COPD with very high $\mathrm{PaCO}$ : a randomized controlled trial. Lung India 2010;27:125-130.

38. Kramer N, Meyer TJ, Meharg J, Cece RD, Hill NS. Randomized, prospective trial of noninvasive positive pressure ventilation in acute respiratory failure. Am J Respir Crit Care Med 1995;151:1799-1806.

39. Martin TJ, Hovis JD, Costantino JP, Bierman MI, Donahoe MP, Rogers $\mathrm{RM}$, et al. A randomized, prospective evaluation of noninvasive ventilation for acute respiratory failure. Am J Respir Crit Care Med 2000;161:807-813.

40. Nava S, Grassi M, Fanfulla F, Domenighetti G, Carlucci A, Perren $A$, et al. Non-invasive ventilation in elderly patients with acute hypercapnic respiratory failure: a randomised controlled trial. Age Ageing 2011;40:444-450.

41. Plant PK, Owen JL, Elliott MW. Early use of non-invasive ventilation for acute exacerbations of chronic obstructive pulmonary disease on general respiratory wards: a multicentre randomised controlled trial. Lancet 2000;355:1931-1935.

42. Schmidbauer W, Ahlers O, Spies C, Dreyer A, Mager G, Kerner T. Early prehospital use of non-invasive ventilation improves acute respiratory failure in acute exacerbation of chronic obstructive pulmonary disease. Emerg Med J 2011;28:626-627.

43. Thys F, Roeseler J, Reynaert M, Liistro G, Rodenstein DO. Noninvasive ventilation for acute respiratory failure: a prospective randomised placebo-controlled trial. Eur Respir J 2002;20:545-555.

44. Osadnik CR, Tee VS, Carson-Chahhoud KV, Picot J, Wedzicha JA, Smith BJ. Non-invasive ventilation for the management of acute hypercapnic respiratory failure due to exacerbation of chronic obstructive pulmonary disease. Cochrane Database Syst Rev 2017;7:CD004-CD104.

45. Carrillo A, Ferrer M, Gonzalez-Diaz G, Lopez-Martinez A, Llamas $\mathrm{N}$, Alcazar $\mathrm{M}$, et al. Noninvasive ventilation in acute hypercapnic respiratory failure caused by obesity hypoventilation syndrome and chronic obstructive pulmonary disease. Am J Respir Crit Care Med 2012;186:1279-1285.

46. Agarwal R, Gupta R, Aggarwal AN, Gupta D. Noninvasive positive pressure ventilation in acute respiratory failure due to COPD vs other causes: effectiveness and predictors of failure in a respiratory ICU in North India. Int J Chron Obstruct Pulmon Dis 2008;3(4):737-743.

47. Keenan SP, Sinuff T, Cook DJ, Hill NS. Which patients with acute exacerbation of chronic obstructive pulmonary disease benefit from noninvasive positive-pressure ventilation? A systematic review of the literature. Ann Intern Med 2003;138:86-70. 
48. Plant PK, Owen JL, Elliott MW. Non-invasive ventilation in acute exacerbations of chronic obstructive pulmonary disease: long term survival and predictors of in-hospital outcome. Thorax 2001;56:708712.

49. Girou E, Brun-Buisson C, Taille S, Lemaire F, Brochard L. Secular trends in nosocomial infections and mortality associated with noninvasive ventilation in patients with exacerbation of COPD and pulmonary edema. JAMA 2003;290:2985-2991.

50. Girou E, Schortgen F, Delclaux C, Brun-Buisson C, Blot F, Lefort Y, et al. Association of noninvasive ventilation with nosocomial infections and survival in critically ill patients. JAMA 2000;284:2361-2367.

51. Diaz GG, Alcaraz AC, Talavera JC, Pérez PJ, Rodriguez AE, Cordoba FG, et al. Noninvasive positive-pressure ventilation to treat hypercapnic coma secondary to respiratory failure. Chest 2005;127:952-960.

52. National association for medical direction of respiratory care. Clinical indications for noninvasive positive pressure ventilation in chronic respiratory failure due to restrictive lung disease, COPD and nocturnal hypoventilation: A consensus conference report. Chest 1999;116:521-534.

53. Bach JR. Conventional approaches to managing neuromuscular ventilatory failure. Henley and Belfus: Philadelphia, PA;1996.

54. Finlay G, Concannon D, McDonnell TJ. Treatment of respiratory failure due to kyphoscoliosis with nasal intermittent positive pressure ventilation (NIPPV). Ir J Med Sci 1995;164:28-30.

55. Sturani C, Galavotti V, Scardeulli C, Sella D, Rosa A, Cauzzi R, et al. Acute respiratory failure, due to severe obstructive sleep apnoeasyndrome, managed with nasal positive pressure ventilation. Monaldi Arch Chest Dis 1994;49:558-560.

56. Shivaram U, Cash ME, Beal A. Nasal continuous positive airway pressure in decompensated hypercapnic respiratory failure as a complication of sleep apnoea. Chest 1993;104:770-774.

57. Barach AL, Martin J, Eckman M. Positive pres-sure respiration and its application to the treatment of acute pulmonary edema. Ann Intern Med 1938;12:754-795.

58. Poulton EP, Oxon DM. Left-sided heart failure with pulmonary oedema its treatment with the 'pulmonary plus pressure machine'. Lancet 1936;228:981-983.

59. Silvers SM, Howell JM, Kosowsky JM, Rokos IC, Jagoda AS, et al. Clinical policy: Critical issues in the evaluation and management of adult patients presenting to the emergency department with acute heart failure syndromes. Ann Emerg Med 2007;49(5):627-669.

60. Gray A, Goodacre S, Newby DE, Masson M, Sampson F, Nicholl J, et al. Noninvasive ventilation in acute cardiogenic pulmonary edema. New Engl J Med 2008;359(2):142-151.

61. Masip J, Roque M, Sanchez B, Fernández R, Subirana M, Expósito JA. Noninvasive ventilation in acute cardiogenic pulmonary edema: Systematic review and meta-analysis. JAMA 2005;294:3124-130.

62. Peter JV, Moran JL, Phillips-Hughes J, Graham P, Bersten AD. Effect of non-invasive positive pressure ventilation (BIPAP) on mortality in patients with acute cardiogenic pulmonary oedema: A meta-analysis. Lancet 2006;367:1155-1163.

63. Vital FM, Ladeira MT, Atallah AN. Non-invasive positive pressure ventilation (CPAP or bilevel NPPV) for cardiogenic pulmonary oedema. Cochrane Database Syst Rev 2013;(3).

64. Aliberti S, Rosti VD, Travierso C, Brambilla AM, Piffer F, Petrelli B, et al. A real life evaluation of non invasive ventilation in acute cardiogenic pulmonary edema: a multicenter, perspective, observational study for the ACPE SIMEU study group. BMC Emerg Med 2018;18(1):61.

65. R Agarwal, A N Aggarwal, D Gupta, Jindal SK. Non-invasive ventilation in acute cardiogenic pulmonary oedema. Postgrad Med J 2005;81:637-643.

66. Kinoshita M, Okayama H, Kawamura G, Shigematsu T, Takahashi T, Kawata Y, et al. Beneficial effects of rapid introduction of adaptive servo-ventilation in the emergency room in patients with acute cardiogenic pulmonary edema. J Cardiol. 2017;69(1):308-313.

67. Rusterholtz T, Bollaert PE, Feissel M, Romano-Girard F, Harlay $\mathrm{ML}$, Zaehringer $\mathrm{M}$, et al. Continuous positive airway pressure vs. proportional assist ventilation for noninvasive ventilation in acute cardiogenic pulmonary edema. Intensive Care Med. 2008;34(5):840846.

68. Agarwal R, Reddy C, Aggarwal AN, Gupta D. Is there a role for noninvasive ventilation in acute respiratory distress syndrome? A meta-analysis. Respir Med 2006;100:2235-2238.

69. Agarwal R, Aggarwal AN, Gupta D. Role of noninvasive ventilation in acute lung injury/acute respiratory distress syndrome: a proportion meta-analysis. Respir Care 2010;55:1653-1660.

70. Thille AW, Contou D, Fragnoli C, Córdoba-Izquierdo A, Boissier F, BrunBuisson C. Non-invasive ventilation for acute hypoxemic respiratory failure: intubation rate and risk factors. Crit Care 2013;17(6):R269.

71. Chawla R, Mansuriya J, Modi N, Pandey A, Juneja D, Chawla A, et al. Acute respiratory distress syndrome: Predictors of noninvasive ventilation failure and intensive care unit mortality in clinical practice. J Crit Care 2016;31(1):26-30.

72. Xu XP, Zhang XC, Hu SL, Xu JY, Xie JF, Liu SQ, et al. Noninvasive ventilation in acute hypoxemic nonhypercapnic respiratory failure: a systematic review and meta-analysis. Crit Care Med 2017;45(7):e727e733.

73. Bellani G, Laffey JG, Pham T, Fan E, Brochard L, Esteban A, et al. Epidemiology, patterns of care, and mortality for patients with acute respiratory distress syndrome in intensive care units in 50 countries. JAMA 2016;315(8):788-800.

74. Bellani G, Laffey JG, Pham T, Madotto F, Fan E, Brochard L, et al. Noninvasive Ventilation of Patients with Acute Respiratory Distress Syndrome. Insights from the LUNG SAFE Study. Am J Respir Crit Care Med 2017;195(1):67-77.

75. He H, Sun B, Liang L, Li Y, Wang H, Wei H, et al. ENIVA study group. A multicenter RCT of noninvasive ventilation in pneumonia-induced early mild acute respiratory distress syndrome. Crit Care 2019;23:300.

76. Hernandez G, Fernandez R, Lopez-Reina P, Cuena R, Pedrosa A, Ortiz $R$, et al. Non-invasive ventilation reduces intubation in chest traumarelated hypoxemia: a randomized clinical trial. Chest 2010;137:74-80.

77. Bolliger CT, Van Eeden SF. Treatment of multiple rib fractures. Randomized controlled trial comparing ventilatory with nonventilatory management. Chest 1990;97:943-948.

78. Gunduz M. A comparative study of continuous positive airway pressure (CPAP) and intermittent positive pressure ventilation (IPPV) in patients with flail chest. Emerg Med J 2005;22:325-329.

79. Keenan SP, Sinuff T, Burns KEA, Muscedere J, Kutsogiannis J, Mehta S, et al. Clinical practice guidelines for the use of noninvasive positivepressure ventilation and noninvasive continuous positive airway pressure in the acute care setting. CMAJ 2011;183(3):E195-E214.

80. Hilbert G, Gruson D, Vargas F, Valentino R, Gbikpi-Benissan G, Dupon $M$, et al. Noninvasive ventilation in immunosuppressed patients with pulmonary infiltrates, fever, and acute respiratory failure. $\mathrm{N}$ Engl J Med 2001;344(7):481-487.

81. Rathi NK, Haque SA, Nates R, Kosturakis A, Wang H, Dong W, et al. Noninvasive positive pressure ventilation vs invasive mechanical ventilation as first-line therapy for acute hypoxemic respiratory failure in cancer patients. J Crit Care 2017;39:56-61.

82. Cortegiani A, Madotto F, Gregoretti C, Bellani G, Laffey JG, Pham T, et al. Immunocompromised patients with acute respiratory distress syndrome: secondary analysis of the LUNG SAFE database. Crit Care 2018;22(1):157.

83. Lemiale V, Mokart D, Resche-Rigon M, Pène F, Mayaux J, Faucher E, et al. Effect of Noninvasive ventilation vs oxygen therapy on mortality among immunocompromised patients with acute respiratory failure: a randomized clinical trial. JAMA 2015;314(16):1711-1719.

84. Azoulay E, Pickkers P, Soares M, Perner A, Rello J, Bauer PR, et al. Acute hypoxemic respiratory failure in immunocompromised patients: the Efraim multinational prospective cohort study. Intensive Care Med 2017;43(12):1808-1819.

85. Huang HB, Xu B, Liu GY, Lin JD, Du B. Use of noninvasive ventilation in immunocompromised patients with acute respiratory failure: a systematic review and meta-analysis. Crit Care 2017;21(1):4.

86. Zayed Y, Banifadel M, Barbarawi M, Kheiri B, Chahine A, Rashdan L, et al. Noninvasive oxygenation strategies in immunocompromised 
patients with acute hypoxemic respiratory failure: a pairwise and network meta-analysis of randomized controlled trials. J Intensive Care Med 2019:885066619844713.

87. Wang T, Zhang L, Luo K, He J, Ma Y, Li Z, et al. Noninvasive versus invasive mechanical ventilation for immunocompromised patients with acute respiratory failure: a systematic review and meta-analysis. BMC Pulm Med 2016;16(1):129.

88. Nava S, Ferrer M, Esquinas A, Scala R, Groff P, Cosentini R, et al. Palliative use of non-invasive ventilation in end-of-life patients with solid tumours: a randomised feasibility trial. Lancet Oncol 2013;14(3):219-227.

89. Jaber S, Chanques G, Jung B. Postoperative noninvasive ventilation. Anaesthesiology 2010;112:453-461

90. Jaber S, Lescot T, Futier E, Paugam-Burtz C, Seguin P, Ferrandiere M, et al. Effect of noninvasive ventilation on tracheal reintubation amongs patients with hypoxemic respiratory failure following abdominal surgery; randomised clinical trial. JAMA 2016;315:1345-1353.

91. Jaber S, Delay J, Chanques G, Sebbane M, Jacquet E, Souche B, et al. Outcome of patients with acute respiratory failure after abdominal surgery treated with non-invasive positive pressure ventilation. Chest 2005;128:2688-2695

92. Ferreyra GP, Baussano I, Squadrone V, Richiardi L, Marchiaro G, Del Sorbo $L$, et al. Continuous positive airway pressure for treatment of respiratory complications after abdominal surgery: a systematic review and meta-analysis. Ann Surg 2008;247(4):617-626.

93. Romero-Corral A, Caples SM, Lopez-Jimenez F, Somers VK. Interactions between obesity and obstructive sleep apnea: implications for treatment. Chest 2010;137:711-719.

94. Lopez PP, Stefan B, Schulman Cl, Byers PM. Prevalence of sleep apnea in morbidly obese patients who presented for weight loss surgery evaluation: more evidence for routine screening for obstructive sleep apnea before weight loss surgery. Am Surg 2008;74:834-838.

95. Sareli AE, Cantor CR, Williams NN, Korus G, Raper SE, Pien G, et al. Obstructive sleep apnea in patients undergoing bariatric surgery--a tertiary center experience. Obes Surg 2011;21:316-327.

96. Gaszynski T, Tokarz A, Piotrowski D, Machala W. Boussignac CPAP in the postoperative period in morbidly obese patients. Obes Surg 2007;17(4):452-456.

97. Pessoa KC, Araujo GF, Pinheiro AN, Ramos MR, Maia SC. Noninvasive ventilation in the immediate postoperative of gastrojejunal derivation with Roux-en-Y gastric bypass. Rev Bras Fisioter 2010;14(4):290-295.

98. Wong DT, Adly E, Ip HY, Thapar S, Maxted GR, Chung FF. A comparison between the Boussignac continuous s positive airway pressure mask and the venturi mask in terms of improvement in the $\mathrm{PaO} 2 / \mathrm{F}(\mathrm{I}) \mathrm{O} 2$ ratio in morbidly obese patients undergoing bariatric surgery: a randomized controlled trial. Can J Anaesth 2011;58(6):532-539.

99. Stefan MS, Hill NS, Raghunathan K, Liu X, Pekow PS, Memtsoudis SG, et al. Outcomes associated with early postoperative noninvasive ventilation in bariatric surgical patients with sleep apnea. J Clin Sleep Med 2016;12(11):1507-1516.

100. Jensen C, Tejirian T, Lewis C, Yadegar J, Dutson E, Mehran A. Postoperative CPAP and BiPAP use can be safely omitted after laparoscopic Roux-en-Y gastric bypass. Surg Obes Relat Dis 2008;4:512-524.

101. Kurrek MM, Cobourn C, Wojtasik Z, Kiss A, Dain SL. Morbidity in patients with or at high risk for obstructive sleep apnea after ambulatory laparoscopic gastric banding. Obes Surg 2011;21:14941498.

102. Tong S, Gower J, Morgan A, Gadbois K, Wisbach G. Noninvasive positive pressure ventilation in the immediate post-bariatric surgery care of patients with obstructive sleep apnea: a systematic review. Surg Obes Relat Dis 2017;13(7):1227-1233

103. Weiss YG, Merin G, Koganov E, Ribo A, Oppenheim-Eden A, Medalion $B$, et al. Postcardiopulmonary bypass hypoxemia: a prospective study on incidence, risk factors, and clinical significance. J Cardiothorac Vasc Anesth 2000;14:506-513.

104. Tenling A, Hachenberg T, Tyden H, Wegenius G, Hedenstierna G. Atelectasis and gas exchange after cardiac surgery. Anesthesiology 1998;89:371-378.
105. Auriant I, Jallot A, Heve P, Cerrina J, Le Roy Ladurie F, Fournier JL, et al Noninvasive ventilation reduces mortality in acute respiratory failure after lung resection. Am J Respir Crit Med 2001;164:1231-1235.

106. Stephan F, Barrucand B, Petit $P$, Rézaiguia-Delclaux $S$, Médard A, Delannoy $B$, et al. High flow nasal oxygen vs noninvasive positive pressure in hypoxemic patients after cardiothoracic surgery: a randomised clinical trial. JAMA 2015;313:2331-2339

107. Zhu G, Huang $Y$, Wei $D$, Shi $Y$. Efficacy and safety of noninvasive ventilation in patients after cardiothoracic surgery. Medicine (Baltimore) 2016;95(38):e4734.

108. Jean-Lavaleur M, Perrier V, Roze H, Sarrabay P, Fleureau C, Janvier $\mathrm{G}$. Stomach rupture associated with noninvasive ventilation. Ann Fr Anesth Reanim 2009;28:588-591

109. Van de Louw A, Brocas E, Boiteau R, Perrin-Gachadoat D, Tenaillon A. Esophageal perforation associated with noninvasive ventilation: a case report. Chest 2002;122:1857-1858

110. Charlesworth M, Lawton T, Fletcher S. Noninvasive positive pressure ventilation for acute respiratory failure following oesophagectomy: Is it safe? A systematic review of the literature. J Intensive Care Soc 2015;16(3):215-221

111. Feltracco P, Serra E, Barbieri S, Milevoj M, Furnari M, Rizzi S, et al ; Noninvasive Ventilation in Postoperative Care of Lung Transplant Recipients. Transplant Proc 2009;41(4):1339-1344.

112. Agarwal R, Khan A, Aggarwal AN, Gupta D. Bronchoscopic Lung Biopsy Using Noninvasive Ventilatory Support: Case Series and Review of Literature of NIV-assisted Bronchoscopy. Respir Care 2012;57(11):1927-1936.

113. Clouzeau B, Bui HN, Guilhon E, Grenouillet-Delacre M, Leger MS, Saghi $\mathrm{T}$, et al. Fiberoptic bronchoscopy under noninvasive ventilation and propofol target-controlled infusion in hypoxemic patients. Intensive Care Med 2011;37:1969-1975.

114. Baumann HJ, Klose H, Simon M, Ghadban T, Braune SA, Hennigs JK, et al. Fiber optic bronchoscopy in patients with acute hypoxemic respiratory failure requiring noninvasive ventilation-a feasibility study. Crit Care 2011;15:R179.

115. Sircar M, Jha OK, Chabbra GS, Bhattacharya S. Noninvasive ventilation assisted bronchoscopy in high risk hypoxemic patients. Indian J Crit Care Med 2019;23(8):363-367.

116. Baillard C, Fosse JP, Sebbane M, Chanques G, Vincent F, Courouble $P$, et al. Noninvasive ventilation improves preoxygenation before intubation of hypoxic patients. Am J Respir Crit Care Med 2006;174:171-177.

117. Jaber S, Jung B, Corne P, Sebbane M, Muller L, Chanques G, et al. An intervention to decrease complications related to endotracheal intubation in the intensive care unit: A prospective, multiple-center study. Intensive Care Med 2010;36:248-255.

118. Futier E, Constantin JM, Pelosi P, Chanques G, Massone A, Petit A, et al. Noninvasive ventilation and alveolar recruitment maneuver improve respiratory function during and after intubation of morbidly obese patients: A randomized controlled study. Anesthesiology 2011;11:1354-1363.

119. Rello J, Rodríguez A, Ibañez P, Socias L, Cebrian J, Marques A, et al. Intensive care adults patients with severe respiratory failure caused by influenza A (H1N1)v in Spain. Crit Care 2009;13:R148.

120. Kumar A, Zarychanski R, Pinto R, CookDJ, Marshall J, Lacroix J, et al. for the Canadian Critical Care Trials Group H1N1 Collaborative. Critically ill patients with 2009 influenza A (H1N1) infection in Canada. JAMA 2009;302:1872-1879.

121. Miller RR, Markewitz BA, Rolfs RT, Brown SM, Dascomb KK, Grissom $\mathrm{CK}$, et al. Clinical findings and demographic factors associated with intensive care unit admission in Utah due to 2009 novel influenza $A$ (H1N1) infection. Chest 2010;137(4):752-758.

122. Masclans JR, Pérez $M$, Almirall J, Lorente $L$, Marqués $A$, Socias $L$, et al. Early non-invasive ventilation treatment for severe influenza pneumonia. Clin Microbiol Infect 2013;19(3):249-256.

123. Rodríguez A, Ferri C, Martin-Loeches I, Díaz E, Masclans JR, Gordo $F$, et al. Risk Factors for Noninvasive Ventilation Failure in Critically III Subjects With Confirmed Influenza Infection. Respir Care 2017;62(10):1307-1315. 
124. Hernández Garcés H, Navarro Lacalle A, Lizama López L, Zaragoza Crespo R. Risk factors associated to noninvasive ventilation failure in primary influenza A pneumonia in the critical care setting. Med Intensiva 2020;pii: S0210-5691(19)30277-3.

125. Aso $\mathrm{H}$, Kondoh $\mathrm{Y}$, Taniguchi $\mathrm{H}$, Kimura $\mathrm{T}$, Nishiyama $\mathrm{O}$, Kato $\mathrm{K}$, et al. Noninvasive ventilation in patients with acute exacerbation of pulmonary tuberculosis sequelae. Intern Med 2010;49(19):2077-2083.

126. Agarwal R, Gupta D, Handa A, Aggarwal AN. Noninvasive ventilation in ARDS caused by Mycobacterium tuberculosis: report of three cases and review of literature. Intensive Care Med 2005;31:1723.

127. Ram FS, Picot J, Lightowler J, Wedzicha JA. Non-invasive positive pressure ventilation for treatment of respiratory failure due to exacerbations of chronic obstructive pulmonary disease. Cochrane Database Syst Rev 2004;(3):CD004104.

128. NICE clinical guidance [CG12]. Chronic obstructive pulmonary disease-Management of chronic obstructive pulmonary disease in adults in primary and secondary care. 2004. http://www.nice.org. uk/guidance/cg12

129. Antonelli M, Conti G, Moro ML, Esquinas A, Gonzalez-Diaz G, Confalonieri $\mathrm{M}$, et al. Predictors of failure of noninvasive positive pressure ventilation in patients with acute hypoxemic respiratory failure: a multi-center study. Intensive Care Med 2001;27(11):17181728.

130. Smith DB, Tay GTP, Hay K, Antony J, Bell B, Kinnear FB, et al. Mortality in acute non-invasive ventilation. Intern Med J 2017;47:1437-1440.

131. Antonelli M, Conti G, Esquinas A, Montini L, Maggiore SM, Bello G, et al. A multiple-center survey on the use in clinical practice of noninvasive ventilation as a first-line intervention for acute respiratory distress syndrome. Crit Care Med 2007;35(1):18-25.

132. Rodríguez A, Ferri C, Martin-Loeches I, Díaz E, Masclans JR, Gordo $\mathrm{F}$, et al. Risk factors for noninvasive ventilation failure in critically ill subjects with confirmed influenza infection. Respir Care 2017;62(10):1307-1315.

133. Carteaux G, Millán-Guilarte T, De Prost N, Razazi K, Abid S, Thille AW, et al. Failure of noninvasive ventilation for de novo acute hypoxemic respiratory failure: role of tidal volume. Crit Care Med 2016;44(2):282290.

134. Frat JP, Ragot S, Coudroy R, Constantin JM, Girault C, Prat G, et al. Predictors of intubation in patients with acute hypoxemic respiratory failure treated with a noninvasive oxygenation strategy. Crit Care Med 2018;46(2):208-215.

135. Corrêa TD, Sanches PR, de Morais LC, Scarin FC, Silva E, Barbas CS, et al. Performance of noninvasive ventilation in acute respiratory failure in critically ill patients: a prospective, observational, cohort study. BMC Pulm Med 2011;15:144.

136. Nava S, Ambrosino N, Bruschi C, Confalonieri M, Rampulla C. Physiological effects of flow and pressure triggering during noninvasive mechanical ventilation in patients with chronic obstructive pulmonary disease. Thorax 1997;52(3):249-254

137. Aslanian P, El Atrous S, Isabey D, Valente E, Corsi D, Harf A, et al. Effects of flow triggering on breathing effort during partial ventilatory support. Am J Respir Crit Care Med 1998;157:135e43.

138. Mehta S, McCool FD, Hill NS. Leak compensation in positive pressure ventilators: A lung model study. Eur Respir J 2001;17:259-267.

139. Rabec C, Rodenstein D, Leger P, Rouault S, Perrin C, Gonzalez-Bermejo $J$, et al. Ventilator modes and settings during non-invasive ventilation: effects on respiratory events and implications for their identification. Thorax 2011; 66:170-178.

140. Cao Z, Luo Z, Hou A, Nie Q, Xie B, An X, et al. Volume-targeted versus pressure-limited noninvasive ventilation in subjects with acute hypercapnic respiratory failure: a multicenter randomized controlled trial. Respir Care 2016;61(11):1440-1450.

141. Calderini E, Confalonieri M, Puccio PG, Francavilla N, Stella L, Gregoretti C. Patient- ventilator asynchrony during noninvasive ventilation: The role of expiratory trigger. Intensive Care Med 1999;25:662-667.

142. Briones Claudett KH, Briones Claudett M, Chung Sang Wong M, Martinez AN, Espinoza RS, Montalvo M, et al. Noninvasive mechanical ventilation with average volume assured pressure support (AVAPS) in patients with chronic obstructive pulmonary disease and hypercapnic encephalopathy. BMC Pulm Med 2013;12;13:12.

143. Çiftci F, Çiledağ A, Erol S, Öz M, Acar D, Kaya A. Evaluation of the feasibility of average volume-assured pressure support ventilation in the treatment of acute hypercapnic respiratory failure associated with chronic obstructive pulmonary disease: A pilot study. J Crit Care 2017;39:232-237.

144. Türk M, Aydoğdu M, Gürsel G. Effects of modes, obesity, and body position on non-invasive positive pressure ventilation success in the intensive care unit: a randomized controlled study. Turk Thorac J 2018;19(1):28-35.

145. Murphy PB, Davidson C, Hind MD, Simonds A, Williams AJ, Hopkinson NS, et al. Volume targeted versus pressure support non-invasive ventilation in patients with super obesity and chronic respiratory failure: a randomised controlled trial. Thorax 2012;67(8):727-734.

146. Selim B, Ramar K. Advanced positive airway pressure modes: adaptive servo ventilation and volume assured pressure support. Expert Rev Med Devices 2016;13(9):839-851.

147. Gay PC, Hess DR, Hill NS. Noninvasive proportional assist ventilation for acute respiratory insufficiency. Comparison with pressure support ventilation. Am J Respir Crit Care Med 2001:164(9):1606-1611.

148. Elganady AA, Beshey BN, Abdelaziz AAH. Proportional assist ventilation versus pressure support ventilation in the weaning of patients with acute exacerbation of chronic obstructive pulmonary disease. Egypt J Chest Dis Tuberc 2014:63(3):653-660.

149. Tirupakuzhi Vijayaraghavan BK, Hamed S, Jain A, Chimunda T, Telias I, Friedrich JO, et al. Evidence Supporting Clinical Use of Proportional Assist Ventilation: A Systematic Review and Meta-Analysis of Clinical Trials. J Intensive Care Med. 2018:885066618769021.

150. Sehgal IS, Kalpakam H, Dhooria S, Aggarwal AN, Prasad KT, Agarwal R. A Randomized Controlled Trial of Noninvasive Ventilation with Pressure Support Ventilation and Adaptive Support Ventilation in Acute Exacerbation of COPD: A Feasibility Study. COPD 2019;16(2):168-173.

151. Sinderby C, Navalesi P, Beck J, Skrobik Y, Comtois N, Friberg S et al. Neural control of mechanical ventilation in respiratory failure. Nat Med 1999;5:1433-1436.

152. Sehgal IS, Dhooria S, Aggarwal AN, Behera D, Agarwal R. Asynchrony index in pressure support ventilation (PSV) versus neurally adjusted ventilator assist (NAVA) during non-invasive ventilation (NIV) for respiratory failure: systematic review and meta-analysis. Intensive Care Med. 2016;42(11):1813-1815.

153. Tajamul S, Hadda V, Madan K, Tiwari P, Mittal S, Khan MA, et al. Neurally-adjusted ventilatory assist versus noninvasive pressure support ventilation in COPD exacerbation: The NAVA-NICE trial. Respir Care 2020;65(1):53-61.

154. Burns KEA, Meade MO, Premji A, Adhikari NK. Noninvasive ventilation as a weaning strategy for mechanical ventilation in adults with respiratory failure: a Cochrane systematic review. CMAJ 2014;186(3):E112-E122.

155. Matsumoto T, Tomii K, Tachikawa R, Otsuka K, Nagata K, Otsuka K, et al. Role of sedation for agitated patients undergoing noninvasive ventilation: clinical practice in a tertiary referral hospital. BMC Pulm Med 2015;15:71.

156. Muriel A, Peñuelas O, Frutos-Vivar F, Arroliga AC, Abraira V, Thille AW, et al. Impact of sedation and analgesia during noninvasive positive pressure ventilation on outcome: a marginal structural model causal analysis. Intensive Care Med 2015;41(9):1586-600.

157. Ni YN, Wang T, Yu H, Liang BM, Liang ZA. The effect of sedation and/ or analgesia as rescue treatment during noninvasive positive pressure ventilation in the patients with Interface intolerance after Extubation. BMC Pulm Med 2017;17:125.

158. Huang Z, Chen YS, Yang ZL, Liu JY. Dexmedetomidine versus midazolam for the sedation of patients with non-invasive ventilation failure. Intern Med 2012;51(17):2299-2305.

159. Clouzeau B, Bui HN, Vargas F, Grenouillet-Delacre M, Guilhon E, Gruson D, et al. Target-controlled infusion of propofol for sedation 
in patients with non-invasive ventilation failure due to low tolerance: a preliminary study. Intensive Care Med 2010;36(10):1675-1680.

160. Rocco M, Conti G, Alessandri E, Morelli A, Spadetta G, Laderchi A, et al. Rescue treatment for noninvasive ventilation failure due to interface intolerance with remifentanil analgosedation: a pilot study. Intensive Care Med 2010;36(12):2060-2065.

161. Coggins AR, Cummins EN, Burns B. Management of critical illness with non-invasive ventilation by an Australian HEMS. Emerg Med J 2016;33(11):807-811.

162. Hui DS, Hall SD, Chan MT, Chow BK, Tsou JY, Joynt GM, et al. Noninvasive positive pressure ventilation: An experimental model to assess air and particle dispersion. Chest 2006;130:730-740.

163. Hui DS, Chow BK, Ng SS, Chu LCY, Hall SD, Gin T, et al. Exhaled air dispersion distances during noninvasive ventilation via different respironics face masks. Chest 2009;136:998-1005.

164. Simonds AK, Hanak A, Chatwin M, Morrell M, Hall A, Parker KH, et al. Evaluation of droplet dispersion during non-invasive ventilation, oxygen therapy, nebuliser treatment and chest physiotherapy in clinical practice: implications for management of pandemic influenza and other airborne infections. Health Technol Assess 2010;14(46):131172

165. Yu IT, Xie ZH, Tsoi KK, Chiu YL, Lok SW, Tang XP, et al. Why did outbreaks of severe acute respiratory syndrome occur in some hospital wards but not in others? Clin Infect Dis 2007;44:1017-1025.

166. Hui DS, Chow BK, Lo T, Ng SS, Ko FW, Gin T, et al. Exhaled air dispersion during noninvasive ventilation via helmets and a total facemask. Chest 2015;147:1336-1343.

167. Hill NS, Carlisle C, Kramer NR. Effect of a non re-breathing exhalation valve on long-term nasal ventilation using a bilevel device. Chest 2002;122:84-91.

168. Conti G, Larrsson A, Nava S, Navalesi P. On the role of non-invasive (NIV) to treat patients during the H1N1 influenza pandemic. Available from: http://dev.ersnet.org/uploads/Document/63/ WEB_CHEMIN_5410_1258624143.pdf.

169. Infection and control of epidemic- and pandemic-prone acute respiratory diseases in health care: WHO Interim Guidelines. Geneva: World Health Organization, 2007. Available from: http://www.who. int/csr/resources/publications/csrpublications/en/index7.html.

170. Lassen HCA. The epidemic of poliomyelitis in Copenhagen. Proc $R$ Soc Med 1954;47(1):67-71.

171. Vanpee D, Delaunois L, Lheureux P. Survey of non- invasive ventilation for acute exacerbation of chronic obstructive pulmonary disease patients in emergency departments in Belgium. Eur J Emerg Med 2002;9:217-224.

172. Nakamura MA, Costa EL, Carvalho CR, Tucci MR. Performance of ICU ventilators during noninvasive ventilation with large leaks in a total face mask: a bench study. J Bras Pneumol 2014;40(3):294-303.

173. Scala R, Naldi M. Ventilators for Noninvasive Ventilation to Treat Acute Respiratory Failure. Respir Care 2008;53(8):1054-1080.

174. Patel RG, Petrini MF. Respiratory muscle performance, pulmonary mechanics, and gas exchange between the BiPAP S/T-D system and the Servo Ventilator $900 \mathrm{C}$ with bilevel positive airway pressure ventilation following gradual pressure support weaning. Chest 1998;114(5):1390-1396.

175. Lofaso F, Brochard L, Hang T, Lorino H, Harf A, Isabey D. Home versus intensive care pressure support devices. Experimental and clinical comparison. Am J Respir Crit Care Med 1996;153(5):1591-1599.

176. Schettino GP, Chatmongkolchart S, Hess DR, Kacmarek RM. Position of exhalation port and mask design affect $\mathrm{CO} 2$ rebreathing during noninvasive positive pressure ventilation. Crit Care Med 2003;31:2178-2182.

177. Thys F, Liistro G, Dozin O, Marion E, Rodenstein DO. Determinants of $\mathrm{FiO} 2$ with oxygen supplementation during noninvasive two-level positive pressure ventilation. Eur Respir J 2002;19:653-657.

178. Ferguson GT, Gilmartin M. CO2 rebreathing during BiPAP ventilatory assistance. Am J Respir Crit Care Med 1995;151:1126-1135.

179. Hill NS, Carlisle C, Kramer NR. Effect of a non re-breathing exhalation valve on long-term nasal ventilation using a bilevel device. Chest 2002;122:84-91.
180. Olivieri C, Costa R, Conti G, Navalesi P. Bench studies evaluating devices for non-invasive ventilation: critical analysis and future perspectives. Intensive Care Med 2012;38:160-167.

181. Fodil R, Lellouche F, Mancebo J, Sbirlea-Apiou G, Isabey D, Brochard $\mathrm{L}$, et al. Comparison of patient-ventilator in terfaces based on their computerized effective dead space. Intensive Care Med 2011;37:257262.

182. Fraticelli AT, Lellouche F, L'Her E, Taillé S, Mancebo J, Brochard L. Physiological effects of different interfaces during noninvasive ventilation for acute respiratory failure. Crit Care Med 2009;37:939945.

183. Navalesi P, Costa R, Ceriana P, Carlucci A, Prinianakis G, Antonelli M, et al. Non-invasive ventilation in chronic obstructive pulmonary disease patients: helmet versus facial mask. Intensive Care Med 2007;33:74-81.

184. VargasF, ThilleA, LyazidiA, Campo FR, Brochard L. Helmet with specific settings versus facemask for noninvasive ventilation. Crit Care Med 2009;37:1921-1928.

185. Liu Q, Gao Y, Chen R, Cheng Z. Noninvasive ventilation with helmet versus control strategy in patients with acute respiratory failure: a systematic review and meta-analysis of controlled studies. Crit Care 2016;20:265.

186. Crimi C, Noto A, Princi P, Esquinas A, Nava S. A European survey of noninvasive ventilation practices. Eur Respir J 2010;36(2):362-369.

187. Silva RM, Timenetsky KT, Neves RC, Shigemichi LH, Kanda SS, Maekawa C, et al. Adaptation to different noninvasive ventilation masks in critically ill patients. J Bras Pneumol 2013;39(4):469-475.

188. Xu XP, Zhang XC, Hu SL, Xu JY, Xie JF, Liu SQ, et al. Noninvasive ventilation in acute hypoxemic nonhypercapnic respiratory failure: a systematic review and meta-analysis. Crit Care Med 2017;45(7):e727e733.

189. Patel BK, Wolfe KS, Pohlman AS, Hall JB, Kress JP, et al. Effect of noninvasive ventilation delivered by helmet vs face mask on the rate of endotracheal intubation in patients with acute respiratory distress syndrome: a randomized clinical trial. JAMA 2016;315(22):2435-2441.

190. Gregoretti C, Confalonieri M, Navalesi P, Squadrone V, Frigerio P, Beltrame $F$, et al. Evaluation of patient skin breakdown and comfort with a new face mask for non-invasive ventilation: A multi-center study. Intensive Care Med 2002;28:278-284.

191. Meduri G, Spencer S. Noninvasive mechanical ventilation in the acute setting. Technical aspects, moni- toring and choice of interface. Eur Respir Monogr 2001;6:106-124

192. Weng, M.H. The effect of protective treatment in reducing pressure ulcers for non-invasive ventilation patients. Intensive Crit Care Nurs 2008;24:295-299.

193. Tai $\mathrm{CH}, \mathrm{Hsu}$ MY. Preventing facial pressure injuries in patients who use noninvasive positive pressure ventilators: the efficiency of dressings. Hu Li Za Zhi 2016;63(5):86-94.

194. Bishopp A, Oakes A, Antoine-Pitterson P, Chakraborty B, Comer D, Mukherjee R. The preventative effect of hydrocolloid dressings on nasal bridge pressure ulceration in acute non-invasive ventilation. Ulster Med J 2019;88(1):17-20.

195. Otero DP, Domínguez DV, Fernández LH, Magariño AS, Gonzalez VJ, Klepzing JV, et al. Preventing facial pressure ulcers in patients under non-invasive mechanical ventilation: a randomised control trial. $J$ Wound Care 2017;26(3):128-136.

196. Cai JY, Zha ML, Chen HL. Use of a hydrocolloid dressing in the prevention of device-related pressure ulcers during noninvasive ventilation: a meta-analysis of randomized controlled trials. Wound Manag Prev 2019;65(2):30-38.

197. Esquinas A, Carrillo A, Gonzalés G, Humivenis Working Group: Absolute humidity variations with a variable inspiratory oxygenation fraction in noninvasive mechanical ventilation. A pilot study. Am J Respir Crit Care Med 2008;177:A644.

198. Lellouche F, Pignataro C, Maggiore SM, Girou E, Deye N, Taillé S, et al. Short-term effects of humidification devices on respiratory pattern and arterial blood gases during noninvasive ventilation. Respir Care 2012;57(11):1879-1886. 
199. Nava S, Navalesi P, Gregoretti C. Interfaces and humidification for noninvasive mechanical ventilation. Respir Care 2009;54(1):71-84.

200. Lellouche F, L'Her E, Abroug F, Deye N, Rodriguez PO, Rabbat A, et al. Impact of the humidification device on intubation rate during noninvasive ventilation with ICU ventilators: results of a multicenter randomized controlled trial. Intensive Care Med 2014;40(2):211-219.

201. Miller DD, Amin MM, Palmer LB, Shah AR, Smaldone GC. Aerosol delivery and modern mechanical ventilation: In vitro/in vivo evaluation. Am J Respir Crit Care Med 2003;168(10):1205-1209.

202. Chatmongkolchart S, Schettino GP, Dillman C, Kacmarek RM, Hess DR. In vitro evaluation of aerosol bronchodilator delivery during noninvasive positive pressure ventilation: Effect of ventilator settings and nebulizer position. Crit Care Med 2003:30(11):2515-2519.

203. Kogo M, Nagata K, Morimoto T, Ito J, Fujimoto D, Nakagawa A, et al. What Is the Impact of Mildly Altered Consciousness on Acute Hypoxemic Respiratory Failure with Non-invasive Ventilation? Intern Med 2018;57:1689-1695.

204. Scala R, Naldi M, Archinucci I,Coniglio G, Nava S. Noninvasive Positive Pressure Ventilation in Patients With Acute Exacerbations of COPD and Varying Levels of Consciousness. Chest 2005;128(3):1657-1666.

205. Scala R, Archinucci I, Naldi M, Donato Alessi S, Fabianelli F, Coniglio G, et al. Non-invasive nasal ventilation in a case of hypercapnic coma. Minerva Anestesiol 1997;63:245-248.

206. Charlesworth M, Elliott MW, Holmes JD. Noninvasive positive pressure ventilation for acute respiratory failure in delirious patients: understudied, underreported, or underappreciated? A systematic review and meta-analysis. Lung 2012;190:597-603.

207. Tanaka LMS, Salluh JIF, Dal-Pizzo F, Barreto BB, Zantieff R, Tobar E, et al. Delirium inintensive care unit patients under noninvasive ventilation: a multinational survey. Rev Bras Ter Intensiva 2015;27(4):360-368.

208. Horvath CM, Brutsche MH, Baty F, Rüdiger JJ. Transcutaneous versus blood carbon dioxide monitoring during acute noninvasive ventilation in the emergency department-A retrospective analysis. Swiss Med Wkly 2016;146:w14373.

209. van Oppen JD, Daniel PS, Sovani MP. What is the potential role of transcutaneous carbon dioxide in guiding acute noninvasive ventilation? Respir Care 2015;60:484-491.

210. Lun CT, Chan VL, Leung WS, Cheung AP, Cheng SL, Tsui MS, et al. A pilot randomized study comparing two methods of non-invasive ventilation withdrawal after acute respiratory failure in chronic obstructive pulmonary disease. Respirology 2013;18:814-819.

211. Hadda V, Kumari R. Protocols for Weaning From NIV: Appraisal of Evidence. Insights Chest Dis. 2016;1:14.

212. Duan J, Tang X, Huang S, Jia J, Guo S. Protocol-directed versus physician-directed weaning from noninvasive ventilation: The impact in chronic obstructive pulmonary disease patients. J Trauma Acute Care Surg 2012;72:1271-1275.

213. Damas C, Andrade C, Araújo JP, Almeida J, Bettencourt P. Weaning from non-invasive positive pressure ventilation: Experience with progressive periods of withdraw. Rev Port Pneumol 2008;14:49-53.

214. Venkatnarayan K, Khilnani GC, Hadda V, Madan K, Mohan A, Pandey $\mathrm{RM}$, et al. A comparison of three strategies for withdrawal of noninvasive ventilation in chronic obstructive pulmonary disease with acute respiratory failure: Randomized trial. Lung India 2020;37:37.

215. Nava S, Gregoretti C, Fanfulla F, Squadrone E, Grassi M, Carlucci A, et al. Noninvasive ventilation to prevent respiratory failure after extubation in high-risk patients. Crit Care Med 2005;33:2465-2470.

216. Khilnani GC, Galle AD, Hadda V, Sharma SK. Non-invasive ventilation after extubation in patients with chronic obstructive airways disease: a randomised controlled trial. Anaesth Intensive Care 2011;39:217223.

217. Girault $C$, Bubenheim $M, A$ broug F, Diehl JL, Elatrous $S$, Beuret $P$, et al. Noninvasive ventilation and weaning in patients with chronic hypercapnic respiratory failure: a randomized multicenter trial. Am J RespirCrit Care Med 2011;184:672-679.

218. Burns KEA, Adhikari NKJ, Meade MO. Noninvasive positive pressureventilation as a weaning strategy for intubated adults with respiratory failure. Cochrane Database Syst Rev 2003;(4):CD004127

219. Esteban A, Frutos-Vivar F, Ferguson ND, Arabi Y, Apezteguía C, González M, et al. Noninvasive positive-pressure ventilation for respiratory failure extubation. N Engl J Med 2004;350:2452-2460.

220. Keenan SP, Powers C, McCormack DG, Block G. Noninvasive positivepressure ventilation for postextubation respiratory distress: a randomized controlled trial. JAMA 2002;287:3238-3244.

221. Lin $\mathrm{C}, \mathrm{Yu} \mathrm{H}$, Fan H, Li Z. The efficacy of noninvasive ventilation in managing postextubation respiratory failure: a meta-analysis. Heart Lung 2014;43(2):99-104. 
'Department of Respiratory and Critical Care Medicine, Indraprastha Apollo Hospitals, New Delhi, India, Phone: +91-9810033395, e-mail: drchawla@hotmail.com

2Department of Critical Care, Sanjeevan \& MJM Hospital, Pune, Maharashtra, India, Phone: +91-9822050240, 020-25531539 / 25539538, e-mail: subhaldixit@gmail.com

${ }^{3}$ Department of Neurotrauma Unit, Ruby Hall Clinic, Pune, Maharashtra, India, Phone: +91-9822844212, e-mail: kapilzirpe@gmail.com

${ }^{4}$ Department of Pulmonary and Critical Care Medicine, PGIMS, Rohtak, Haryana, India, Phone: +91-9991101616, e-mail: dhruvachaudhry@yahoo. co.in

${ }^{5}$ Department of PSRI Institute of Pulmonary, Critical Care and Sleep Medicine, PSRI Hospital, New Delhi, India, Phone: +91-9810 353 696, e-mail: gckhil@gmail.com

${ }^{6}$ Department of Medanta Institute of Critical Care and Anesthesiology, Medanta The Medicity, Sector-38, Gurgaon-122001, Haryana, India, Phone: + 911244141414 Extn. 3335, e-mail: yatinmehta@hotmail.com

${ }^{7}$ Department of Medicine, SKN Medical College, Pune, Maharashtra, India, Phone: +91-9822091745, e-mail: drkhatibkhalid@gmail.com

${ }^{8}$ Department of Critical Care, Reliance Hospital, Navi Mumbai, Maharashtra, India, Phone: 9766363200, e-mail: bharatjigiasi@yahoo.com

${ }^{9}$ Department of Critical Care Medicine, Bhatia Hospital, Mumbai, Maharashtra, India, Phone: 9757169559, e-mail: gunj80@gmail.com

${ }^{10}$ Department of Critical Care, Saneejivini Hospital, Vastrapur, Ahmedabad, Gujarat, India, Phone: +91-9924231500, e-mail: mishr.c@gmail.com

${ }^{11}$ Department of Critical Care ,Virinchi Hospital , Hyderabad, Telangana, India, Phone: 9866343632, e-mail: srinivas3271@gmail.com

${ }^{12}$ Department of Critical Care, Medanta Hospital, The Medicity, Gurugram, Haryana, India, Phone: 91-11-26692531, e-mail: drdeepak_govil@ yahoo.co.in

${ }^{13}$ Department of Critical Care Medicine, Narayana Superspeciality Hospital, Gurugram, Haryana, India, Phone: +91-9873240734, e-mail: dr_ sachin78@yahoo.co.in

${ }^{14}$ Department of Critical Care, Prayag Hospital, Pune, Maharashtra, India, Phone: 91-20-25534448, e-mail: shirishprayag@gmail.com

${ }^{15}$ Department of Critical Care, Apollo Gleneagles Hospital Limited, Kolkata, India, Phone: +91-33-23203040, e-mail: drsuresh@hotmail.com

${ }^{16}$ Department of critical care, Synergy Hospital Rajkot, Rajkot, Gujarat, India, Phone: +91-9825043590, e-mail: jayeshdobariya@yahoo.co.in

${ }^{17}$ Department of Pulmonary, Critical Care and Sleep Medicine, Military Hospital (CTC), Pune, Maharashtra, India, Phone: 9560503335 , e-mail: docvikasmarwah@gmail.com

${ }^{18}$ Department of Pulmonary Medicine, Postgraduate Institute of Medical Education and Research, Sector 12, Chandigarh, India, Phone: $0172-$ 2756823, e-mail: inderpgi@outlook.com

${ }^{19}$ Department of Critical Care, Deenanath Mangeshkar Hospital, Pune, Maharashtra, India, Phone: 91-9823018178, 91-9823018178, e-mail: drjogs@gmail.com

${ }^{20}$ Department of Division of Critical Care Medicine, Department of Anaesthesia, Critical Care and Pain, Tata Memorial Hospital, Homi Bhabha National Institute, Mumbai, Maharashtra, India, Phone: 91-9869077526, e-mail: kaivalyaak@yahoo.co.in 